'National CJD Research \& Surveillance Unit, Centre for Clinical Brain Sciences, University of Edinburgh, Edinburgh, UK.

${ }^{2}$ Cellule Nationale de référence des MCJ, Groupe Hospitalier Pitié-Salpêtrière, Paris, France.

${ }^{3}$ National Reference Centre for TSE, Department of Neurology, University Medical Centre Göttingen, Göttingen, Germany.

${ }^{4}$ Registry of Creutzfeldt-Jakob Disease, Department of Neuroscience, Istituto Superiore di Sanità,

Rome, Italy.

凶e-mail:suvankar.pal@ ed.ac.uk

https://doi.org/10.1038 \$41582-021-00488-7

\title{
The importance of ongoing international surveillance for Creutzfeldt-Jakob disease
}

Neil Watson ${ }^{1}$, Jean-Philippe Brandel ${ }^{2}$, Alison Green ${ }^{1}$, Peter Hermann ${ }^{3}$, Anna Ladogana ${ }^{4}$, Terri Lindsay ${ }^{1}$, Janet Mackenzie', Maurizio Pocchiari ${ }^{4}{ }^{4}$, Colin Smith ${ }^{1}$, Inga Zerr ${ }^{3}$ and Suvankar Pal@ ${ }^{1 凶}$

Abstract $\mid$ Creutzfeldt-Jakob disease (CJD) is a rapidly progressive, fatal and transmissible neurodegenerative disease associated with the accumulation of misfolded prion protein in the CNS. International CJD surveillance programmes have been active since the emergence, in the mid-1990s, of variant CJD (VCJD), a disease linked to bovine spongiform encephalopathy. Control measures have now successfully contained bovine spongiform encephalopathy and the incidence of $\mathrm{vCJD}$ has declined, leading to questions about the requirement for ongoing surveillance. However, several lines of evidence have raised concerns that further cases of $\mathrm{VCJD}$ could emerge as a result of prolonged incubation and/or secondary transmission. Emerging evidence from peripheral tissue distribution studies employing high-sensitivity assays suggests that all forms of human prion disease carry a theoretical risk of iatrogenic transmission. Finally, emerging diseases, such as chronic wasting disease and camel prion disease, pose further risks to public health. In this Review, we provide an up-to-date overview of the transmission of prion diseases in human populations and argue that CJD surveillance remains vital both from a public health perspective and to support essential research into disease pathophysiology, enhanced diagnostic tests and much-needed treatments.

Creutzfeldt-Jakob disease (CJD) is a devastating and uniformly fatal human prion disease. The disease typically causes a combination of cognitive and motor dysfunction and is associated with rapid progression, with the majority of affected individuals dying within several months of symptom onset ${ }^{1-5}$. Sporadic CJD (sCJD) is the archetypal human prion disease, belonging to a family of transmissible and universally lethal mammalian diseases ${ }^{6}$. The discovery that prion diseases are associated with the conversion of normal host-encoded cellular prion protein $\left(\mathrm{PrP}^{\mathrm{C}}\right)$ to a misfolded form $\left(\mathrm{PrP}^{\mathrm{Sc}}\right)$ by post-translational modification, independently of nucleic acid, became known as the protein-only hypothesis. It was Stanley Prusiner who discovered and characterized prions, for which he received a Nobel Prize in 1997 (REF.7). Prion diseases are transmissible and multiple epidemics affecting humans and animals have emerged globally over the last 50 years ${ }^{5,8-14}$. A hallmark of prion disease transmission is the potential for incubation phases lasting several years, sometimes decades ${ }^{5,9,15,16}$.

A polymorphism at codon 129 (c129) in the prion protein gene (PRNP) strongly influences the susceptibility towards and the clinical features of human prion diseases ${ }^{1,9,10,17-20}$. Over $90 \%$ of East Asian individuals are homozygous for methionine at c129 (MM genotype); however, in populations of European descent, $40 \%$ of individuals have the MM genotype, $50 \%$ of individuals are heterozygous for methionine and valine (MV genotype), and $\sim 10 \%$ are homozygous for valine (VV genotype) ${ }^{21}$. The treatment of tissue samples with proteinase $\mathrm{K}$ followed by western blot examination enables the detection of protease-resistant fragments of $\operatorname{PrP}^{\mathrm{Sc}}\left(\mathrm{PrP}^{\mathrm{res}}\right)$ in individuals with prion disease, providing a 'molecular signature' of the disease $\mathrm{e}^{22}$. $\mathrm{PrP}^{\mathrm{res}}$ is biochemically classified according to the molecular weight of the unglycosylated fragment, which is $21 \mathrm{kDa}$ in type $1 \mathrm{PrP}^{\mathrm{res}}$ and $19 \mathrm{kDa}$ in type $2 \mathrm{PrP}^{\mathrm{res}}\left(\mathrm{REFS}^{22,23}\right)$. Type 2 is further classified into types $2 \mathrm{~A}$ and $2 \mathrm{~B}$; the latter is characterized by a predominant diglycosylated band and is present in individuals with variant CJD (vCJD) ${ }^{23}$. Prion diseases can be classified according to the system suggested by Parchi et al. ${ }^{17}$, which is based on a combination of the 129 genotype and $\mathrm{PrP}^{\mathrm{res}}$ isotype, providing biological correlates for clinical manifestations of disease $\mathrm{e}^{24}$.

CJD consists of three subtypes: sporadic, inherited and acquired (comprising iatrogenic CJD (iCJD), vCJD 


\section{Key points}

- Creutzfeldt-Jakob disease (CJD) is a transmissible and universally fatal human prion disease; surveillance programmes exist globally to monitor trends in CJD epidemiology and mitigate public health risks.

- The variant CJD (vCJD) epidemic was a devastating consequence of the bovine spongiform encephalopathy (BSE) epizootic.

- Studies indicate the widespread prevalence of $\mathrm{vCJD}$-associated prion protein in BSE-exposed populations.

- Although new diagnoses of $\mathrm{V} C J \mathrm{D}$ have declined in parallel with the suppression of BSE, lessons from other prion diseases indicate the potential for highly extensive incubation phases lasting decades.

- Emerging animal prion diseases might harbour the potential for zoonotic transmission to humans.

- Continued CJD surveillance is a necessity to meet the potential for further cases of $\mathrm{vCJD}$ or the emergence of novel prion diseases in humans.

and Kuru). All forms of CJD are transmissible and thus pose serious public health challenges. vCJD was first detected in 1996, initially in the $\mathrm{UK}^{25}$ and subsequently in France ${ }^{26}$, and was causally linked to the epizootic of bovine spongiform encephalopathy (BSE), a prion disease affecting cattle. The incidence of vCJD has dramatically declined since the global vCJD epidemic peaked in 2000; seven new cases of the disease have been identified globally since 2012 (REFS ${ }^{10,16,20,27,28}$ ) (FIG. 1). As CJD clinical surveillance programmes were developed in response to the emergence of BSE in cattle, the question of whether CJD surveillance is still necessary has now emerged. In this Review, we discuss the evidence indicating that further cases of VCJD could arise as a result of extensive incubation, asymptomatic carriage of vCJD-associated prion protein and secondary transmission. We also discuss the potential for secondary transmission of other forms of CJD, occupational risks, emerging prion diseases with zoonotic potential and the growing evidence that other neurodegenerative diseases could harbour the potential for prion-like transmissibility. We highlight the importance of surveillance programmes for accurate case ascertainment, public health interventions and much-needed research into prion diseases. Last, we provide the outline for a model surveillance programme and suggestions for how international surveillance should progress in the twenty-first century.

\section{Clinical subtypes of prion disease Sporadic CJD}

In the majority ( $~ 85 \%)$ of individuals who develop CJD, the disease arises sporadically ${ }^{1,29-31}$. The onset of sCJD is most common between the ages of 60 and 70 years $^{32}$, although cases have been identified across a range of age groups $^{1}$. sCJD has been detected in Europe ${ }^{1,17,29,30,33,34}$, North America $^{31}$, Central America ${ }^{35}$, South America ${ }^{36,37}$, Africa $^{38-40}$, Asia $^{41-45}$ and Australasia ${ }^{33,46,47}$, and has a global incidence of 1-2 per million, although the reported incidence varies between nations and is influenced by the methods and extent of surveillance performed $^{2}$. Multiple low-income and middle-income countries have reported cases of sCJD ${ }^{37-40,43,48,49}$; however, as surveillance programmes are absent across much of the world, accurate epidemiological assessment is extremely challenging ${ }^{21}$.
The aetiology of sCJD is unknown; however, the leading hypothesis is of an endogenous origin via a somatic mutation in PRNP or, alternatively, the spontaneous misfolding of $\operatorname{PrP}^{\mathrm{C}}$ into $\operatorname{PrP}^{\mathrm{Sc}}\left(\mathrm{REF}^{50}{ }^{50}\right.$. Some case-control studies have suggested the presence of exogenous risk factors. For example, two studies identified an association between sCJD and previous surgery ${ }^{51,52}$, including non-neurosurgical (particularly ophthalmologic) operations. Another study found an association between sCJD and previous blood-product transfusion ${ }^{53}$. However, such case-control studies of sCJD have methodological limitations, including the potential for various forms of bias such as recall bias, differences in risk factor reporting (in contrast to healthy controls, most individuals with SCJD are unable to provide a direct history, leading to a reliance on relatives to provide information), and heterogeneity between studies in terms of the time windows of exposure assessed ${ }^{52,53}$. A detailed comparison of 18 studies is provided in a 2012 systematic review by de Pedro Cuesta et al. ${ }^{54}$. Evidence indicates that the c129 genotype has a substantial impact on susceptibility to SCJD: $\sim 70 \%$ of individuals with sCJD have the MM genotype $^{17,55}$.

sCJD classically presents as a rapidly progressive dementia with motor decline that includes ataxia as well as pyramidal and extrapyramidal features; however, symptoms can include visual disturbance (most notably in the Heidenhain subtype ${ }^{56}$ ), neuropsychiatric manifestations and stroke-like presentations ${ }^{24}$. Myoclonus is common and patients eventually progress to an akinetic, mute, fully dependent state. Diagnostic classification follows the European Creutzfeldt-Jakob Disease Surveillance Network criteria ${ }^{57}$ (BOX 1). Diagnosis is based on the presence of typical clinical features, supported by evidence from additional investigations. This supporting evidence includes the identification of characteristic MRI changes in the basal ganglia and/or cortex $^{58,59}$ (FIG. 2), EEG showing characteristic periodic sharp wave complexes ${ }^{60}$, elevated levels of 14-3-3 protein in cerebrospinal fluid (CSF) $)^{61-63}$ and the detection of $\mathrm{PrPsc}^{\mathrm{sc}}$ in CSF using real-time quaking-induced conversion (RT-QuIC) (an aggregation assay with almost $100 \%$ specificity for the diagnosis of sCJD) ${ }^{64-66}$. The neuropathology of CJD is characterized by vacuolation and/or spongiform change, neuronal loss, gliosis, and the immunohistochemical detection of $\mathrm{PrP}^{\mathrm{Sc}}$ (REFS ${ }^{17,67,68}$ ). The median survival for individuals with sCJD is 5 months from symptom onset ${ }^{24}$. sCJD can be categorized by $\mathrm{c} 129$ genotype and $\mathrm{PrP}^{\mathrm{Sc}}$ isotype into six subgroups (MM1, MM2, MV1, MV2, VV1 and VV2) each with characteristic clinical and neuropathological phenotypes $^{17,58}$ (FICS 3,4).

\section{Inherited prion diseases}

In $10-15 \%$ of individuals with a prion disease ${ }^{3,469}$, the disease arises secondary to mutations in PRNP and is categorized as inherited prion disease (IPD) ${ }^{69}$. Over 50 prion disease-associated PRNP mutations have now been described ${ }^{24,69}$. Most of these mutations show autosomal dominant inheritance and high penetrance, although some individuals with IPD do not have a family history of the disease ${ }^{3,69}$. IPD is associated with a longer 


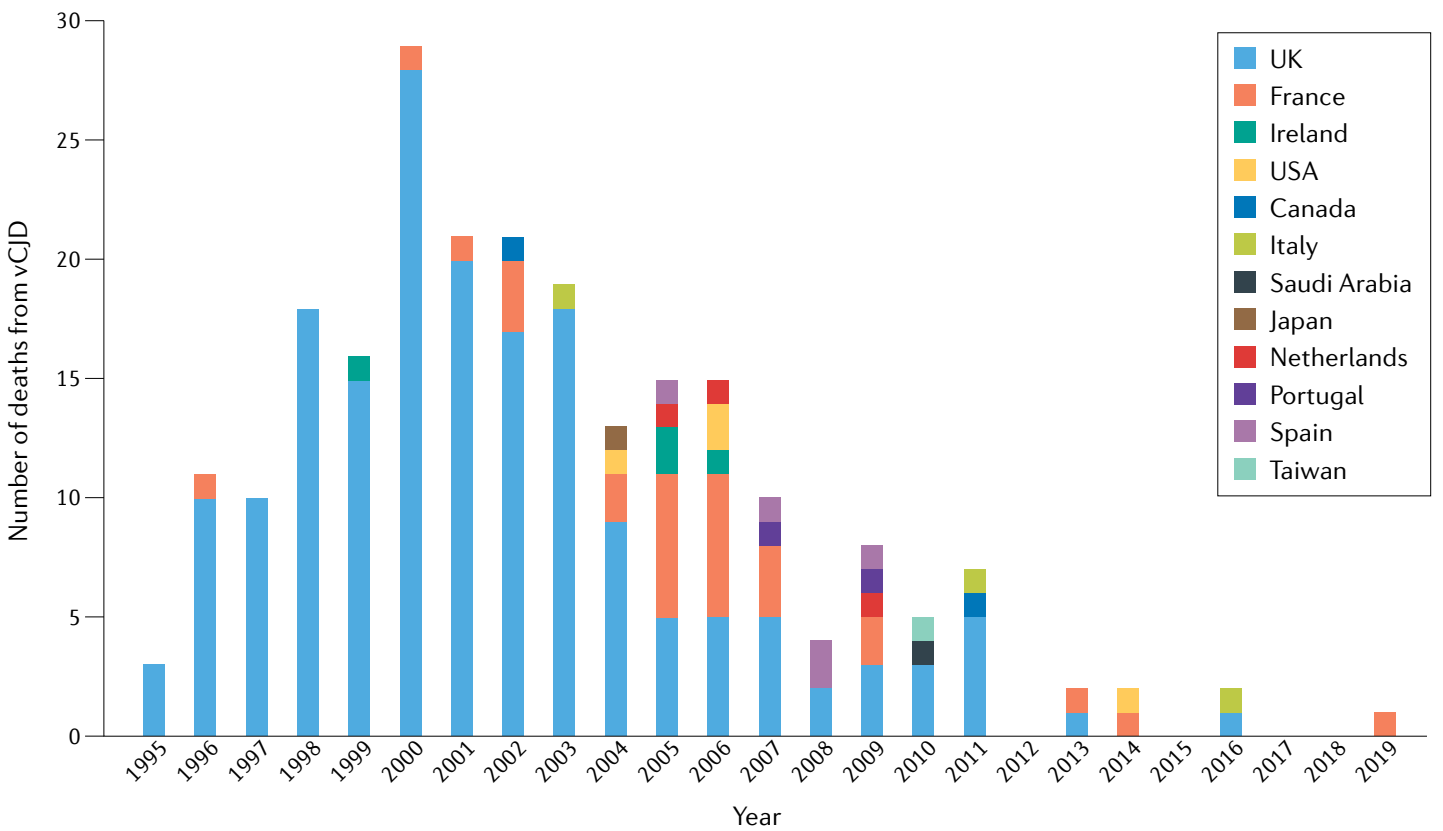

Fig. 1 | The global burden of vCJD. Graph shows the annual number of deaths from variant Creutzfeldt-Jakob disease (vCJD) in the 12 countries or territories for which data is available. Data obtained from the European Creutzfeldt-Jakob Disease Surveillance Network (EuroCJD).

survival than $\mathrm{SCJD}$, which means that individuals with IPD comprise a substantial proportion of the prevalent population ${ }^{70}$. This prevalence is accompanied by public health risks relating to transmission. In some individuals, IPD can be difficult to distinguish from sCJD based on clinical characteristics and therefore diagnostic PRNP genotyping is often helpful. The extent of the public health risk posed by asymptomatic $P R N P$ mutation carriers during interventional procedures and/or blood or tissue donation is not yet clear; risk-reduction measures for these individuals are in place in many countries ${ }^{71,72}$.

Considerable heterogeneity in age of onset, duration of disease and clinical features exists between individuals with different PRNP mutations as well as between family members with the same mutation ${ }^{69}$. The clinical features of IPD can also mimic other neurodegenerative disorders ${ }^{69,73}$; symptoms can resemble Alzheimer disease $^{74}$, Huntington disease ${ }^{75-77}$, frontotemporal dementia $^{78,79}$ and spinocerebellar ataxia ${ }^{76}$. Individuals with IPD associated with the E200K mutation in PRNP often have a clinical presentation that mimics SCJD, with rapid progression from symptom onset to death in $<5$ months $^{3}$. Individuals with mutations, such as E200K, that are associated with an sCJD phenotype are referred to as having genetic CJD (gCJD). GerstmannStraussler-Scheinker syndrome, which is most commonly caused by the P102L mutation in PRNP, causes a progressive ataxia with associated cognitive and sensory abnormalities $^{76}$ and has characteristic neuropathological features (FIG. 5). The disease typically progresses more slowly than SCJD, with a mean survival of 49 months from symptom onset ${ }^{76}$. Fatal familial insomnia, a result of the $\mathrm{D} 178 \mathrm{~N}$ mutation in combination with methionine at c129 on the affected allele (D178N-129M), presents with characteristic sleep disorders, autonomic disease, and gait disturbance and is typically fatal within 2 years of onset ${ }^{80}$. By contrast, individuals with D178N and valine at $\mathrm{c} 129$ on the affected allele (D178-129V) develop gCJD ${ }^{81}$.

Surveillance systems have greatly enhanced our understanding of the international distribution of IPD-associated mutations $s^{3,41,82,83}$, yielding valuable insights. E200K is the most common mutation internationally ${ }^{3,82}$ but is particularly common in Slovakia, where it is present in $>65 \%$ of individuals with prion disease ${ }^{3}$, and in Jewish individuals with Libyan ancestry, a population prevalent in Israel ${ }^{84}$. Evidence indicates that, in Italy, a nation with a relatively high rate of IPD $^{3}$, the V210I mutation is the most frequent and is present in $41.5 \%$ of individuals with IPD ${ }^{85}$. Fatal familial insomnia has been observed in Europe, Asia, Australia and the USA $^{3,21,80,83,86}$. T188K is a common cause of IPD in China, where it is present in $23 \%$ of affected individuals ${ }^{83}$, but is uncommon elsewhere, including other Asian nations such as Japan ${ }^{41}$ and Korea ${ }^{87}$ where no individuals with the mutation were identified in published IPD case series. Ongoing global surveillance continues to identify novel mutations associated with prion disease, often showing small clusters within regions; for example, the identification of a cohort of individuals with $\mathrm{R} 208 \mathrm{H}$ in Sardinia, which suggests a founder population ${ }^{88}$. V180I and M232R are commonly encountered in Japanese individuals with IPD, comprising $41.2 \%$ and $15.3 \%$ of PRNP variants, respectively ${ }^{41}$. However, V180I and M232R might increase the susceptibility to sCJD rather than being disease-causing mutations $s^{69,89}$. Some authors ${ }^{89}$ have cited factors, including the sCJD-like phenotype and the absence of a relevant family history among affected individuals (present in only $2 \%$ of individuals with V180I and in $0 \%$ with $\mathrm{M} 232 \mathrm{R}^{41}$ ), as evidence that 
Box 1 | European Creutzfeldt-Jakob Disease Surveillance Network diagnostic criteria for sCJD

\section{Definite sCJD:}

Progressive neurological syndrome and either neuropathological, immunocytochemical or biochemical confirmation.

\section{Probable sCJD:}

Rapidly progressive cognitive impairment; two of myoclonus, visual or cerebellar problems, pyramidal or extrapyramidal features, and akinetic mutism; and typical EEG ${ }^{\text {. }}$

\section{OR}

Rapidly progressive cognitive impairment; two of myoclonus, visual or cerebellar problems, pyramidal or extrapyramidal features, and akinetic mutism; and typical MRI brain scan ${ }^{\mathrm{b}}$.

\section{OR}

Rapidly progressive cognitive impairment; two of myoclonus, visual or cerebellar problems, pyramidal or extrapyramidal features, and akinetic mutism; and positive cerebrospinal fluid 14-3-3 protein test.

\section{OR}

Progressive neuropsychiatric syndrome and positive real-time quaking-induced conversion (RT-QuIC) in cerebrospinal fluid or other tissues.

\section{Possible sCJD:}

Rapidly progressive cognitive impairment; two of myoclonus, visual or cerebellar problems, pyramidal or extrapyramidal features, and akinetic mutism; and duration $<2$ years

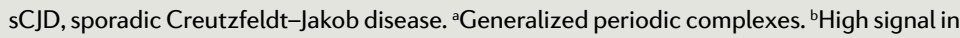
caudate and/or putamen on MRI brain scan or at least two cortical regions (temporal, parietal, occipital) either on diffusion-weighted imaging or fluid-attenuated inversion recovery. Adapted from REF. ${ }^{269}$, CC BY 4.0 (https://creativecommons.org/licenses/by/4.0/).

V180I and M232R might be polymorphisms rather than pathogenic mutations. IPD has been reported in South America $^{90}$ and India ${ }^{91}$; however, a lack of structured surveillance programmes in these regions means that prevalence remains unclear.

\section{Acquired prion diseases}

Kuru. Fewer than 5\% of individuals diagnosed with $\mathrm{CJD}^{7}$ have one of the acquired prion diseases, which consist of iCJD, vCJD and $\mathrm{Kuru}^{2,92}$. To date, Kuru has only been detected in the Fore people in Papua New Guinea, in whom an epidemic of the disease was caused by ritualistic mortuary cannibalism ${ }^{8,9,93,94}$. The Kuru epidemic is thought to have started in the 1920s and peaked in the late $1950 \mathrm{~s}^{8,9}$. The epidemic subsided following the prohibition of cannibalism in the mid-1950s, ever, in some individuals heterozygous at c129, Kuru did not manifest until several decades after exposure ${ }^{9}$. This observation demonstrates the risk of extensive incubation times in acquired prion diseases.

Iatrogenic CJD. iCJD was first described in 1974 in an individual who had received a transplant of corneal tissue from a deceased donor, in whom SCJD was later identified at autopsy ${ }^{95}$. Subsequent cases of iCJD were traced to a number of causes. The two principal aetiologies are treatment with cadaveric pituitary-derived human growth hormone (c-hGH) ${ }^{96}$ and human dura mater (hDM) grafts ${ }^{5}$. Less commonly, iCJD has arisen secondary to treatment with cadaveric gonadotropins ${ }^{97}$ and following exposure to contaminated neurosurgical instruments and intracerebral depth electrodes ${ }^{24}$.
The iatrogenic transmission of vCJD via blood products (discussed in more detail below) is typically considered separately to iCJD owing to major differences in the pathology and manifestations of the two diseases. Despite effective control measures, including a transition to recombinant hormone synthesis in the mid-1980s $\mathrm{s}^{5,15,98}$, the introduction of enhanced disinfection and processing of hDM grafts in $1987\left(\mathrm{REFS}^{99,100}\right)$, shifts in neurosurgical practice away from hDM graft usage $^{101}$, and the sterilization and quarantine of infected instruments ${ }^{71,102}$, individuals with iCJD are still being reported $^{1,100}$. For some of these individuals, exposure to the prion protein was more than four decades before disease manifestation ${ }^{103}$, highlighting the potential for extensive incubation periods $\mathrm{s}^{5,15,98}$.

The hDM-associated iCJD epidemic began in 1985 and peaked globally in 1997 (REF. ${ }^{5}$ ), although cases continue to be identified ${ }^{100}$. The epidemic arose largely from the use of Lyodura, a hDM product produced in Germany $y^{5,100,104}$. The region with the largest number of hDM-associated iCJD cases (154 as of March 2018 (REF. $\left.{ }^{100}\right)$ ) was Japan, where high numbers of hDM-grafting procedures were performed, although cases were also reported in other Asian nations, Europe, the USA, Australasia and South Africa ${ }^{5}$.

c-hGH-associated iCJD was most frequently encountered in France ${ }^{29}$, the $\mathrm{UK}^{1}$ and the USA ${ }^{105}$, and less commonly in other European countries, New Zealand, Qatar and Brazil ${ }^{5}$. The epidemic began in 1984 and peaked globally in 1995 (REF. ${ }^{5}$ ); individuals with extensive incubation continue to be reported ${ }^{15}$. The majority of individuals who developed c-hGH-associated iCJD in France had the MM c129 genotype whereas, in the $\mathrm{UK}$, the VV and MV genotypes were more common ${ }^{5,106}$. $\mathrm{c}$-hGH-associated iCJD is believed to have originated from the preparation of $\mathrm{c}-\mathrm{hGH}$ from cadaveric sources likely to have had undetected $\mathrm{sCJD}^{15}$. Therefore, the presence of different $\mathrm{PrP}^{\mathrm{Sc}}$ strains in different cadaveric sources might have contributed to the differing susceptibility to c-hGH-associated iCJD among c129 genotype groups in the UK and France ${ }^{15}$.

Important lessons have been learned from the study of iCJD. The incubation period varies, being shortest following exposure to contaminated neurosurgical instruments and longest following exposure to hDM grafts and cadaveric hormones ${ }^{5}$. However, incubation rates also vary between individuals with the same means of exposure $^{5}$. For example, individuals with the MV c129 genotype tend to show longer iCJD incubation periods than individuals with other c129 genotpyes ${ }^{5}$. These insights are relevant to vCJD as legitimate concerns exist that future cases of vCJD could emerge following extensive incubation periods. Long incubation periods are also relevant when considering the potential of secondary transmission of all forms of CJD. The clinical manifestations of iCJD are variable, with peripheral exposures frequently leading to cerebellar-onset presentations and central exposures leading to cognitive-onset manifestations ${ }^{5}$. Last, as a general historical point, medical and agricultural practices that unknowingly posed infection risks at the time have subsequently resulted in the emergence of prion disease, sometimes many years 
later. The prompt identification of individuals with iCJD through surveillance was integral to the implementation of the measures that contained the resulting epidemics, illustrating the essential role for surveillance systems in managing novel prion disease epidemics.

Variant CJD. vCJD is the rarest form of human prion disease and was first recognized between 1995 and 1996 following the identification of a series of individuals in the UK with a novel prion disease characterized by atypical demographic, clinical, radiological and pathological features $^{25,107}$ (BOX 2). vCJD predominantly presents in the third decade of life and has a median survival period of 14 months, which is longer than that of sCJD ${ }^{108}$. In vCJD, early psychiatric symptoms including withdrawal, anxiety and dysphoria are common before the development of cognitive impairment, ataxia and movement disorders ${ }^{109,110}$. Thalamic pain affects many individuals in the early stages of the disease ${ }^{109}$. The presence of the pulvinar sign on MRI is a highly sensitive marker of vCJD in the appropriate context ${ }^{111}$. The detection of high levels of 14-3-3 protein in the CSF, which is a biomarker with $75-90 \%$ sensitivity for SCJD, only shows a $50 \%$ sensitivity for vCJD ${ }^{112}$. Furthermore, EEG in individuals with vCJD does not typically show the characteristic periodic sharp wave complexes that are observed in $\mathrm{sCJD}^{24}$. vCJD neuropathology is characterized by florid plaques and extensive type 2B PrPres (REF. ${ }^{68,113}$ ) (FICS 4,6).

Surveillance programmes accurately mapped case ascertainment and the trajectory of the vCJD epidemic, which was focused primarily in the UK (178 cases) and France (28 cases). At the time of writing (March 2021), a total of 232 cases of vCJD have been identified from 12 countries or territories across Europe, the USA, the

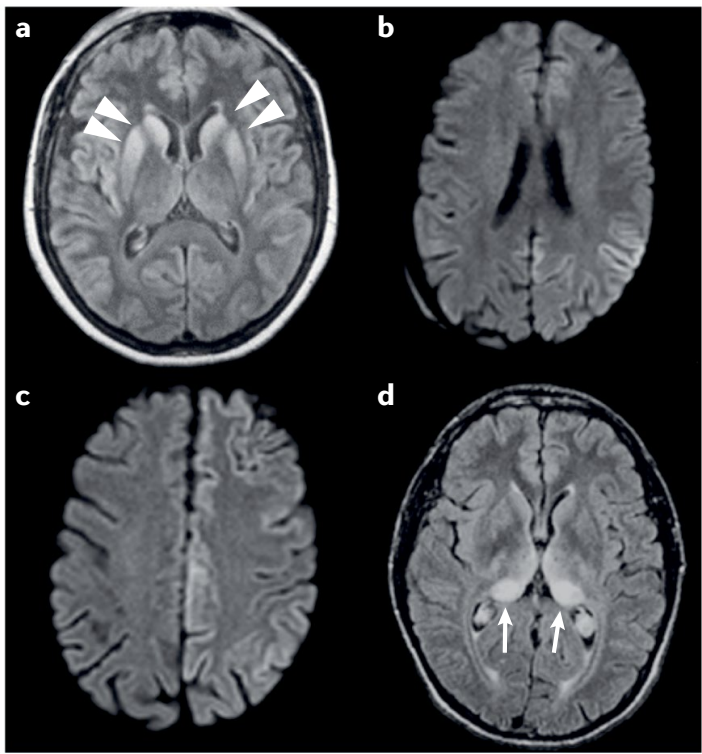

Fig. 2 | Brain MRI in individuals with CJD. Bilateral basal ganglia hyperintensities (arrowheads) are seen in sporadic Creutzfeldt-Jakob disease (CJD) (part a). Multifocal cortical ribboning can be seen in sporadic CJD, visible in the parietal (part b) and interhemispheric (part c) cortex in this individual. Bilateral pulvinar hyperintensities (arrows), known as the pulvinar sign, are seen in variant CJD (part d).
Middle East and Asia ${ }^{10}$ (FIG. 1). vCJD was causally linked to the epizootic of BSE, a novel prion disease affecting cattle, with the consumption of contaminated beef products being the primary source of VCJD infection ${ }^{92,114,115}$.

The BSE epizootic arose as a result of agricultural feeding practices that involved using ruminant-derived rendered meat-and-bone meal (MBM) to feed cattle ${ }^{11}$. However, the origin of BSE itself remains unclear. The most popular hypothesis is that material from a scrapie-infected sheep entered the cattle feed supply, with the scrapie agent becoming altered on passage through cattle, rendering it highly infectious ${ }^{11,116}$. Alternative hypotheses, which have garnered less consensus, include the scrapie agent being altered by the rendering process or the emergence of a novel transmissible spongiform encephalopathy in the UK, possibly in cattle, which then entered the ruminant feed chain ${ }^{11}$. The epizootic peaked in 1992 in the UK, with 37,280 new cases identified in cattle that year ${ }^{12}$. A host of stringent control measures were adopted ${ }^{117-121}$. In the UK, these measures consisted of a ban on feeding ruminant-derived protein to ruminants (1988) ${ }^{122}$; surveillance, reporting and culling of BSE-infected animals $(1988)^{122}$; a ban on feeding specified bovine offal to humans $(1989)^{122}$; and a ban on feeding specified bovine offal to all farmed animals $(1990)^{122}$. The EU also introduced a ban on feeding mammalian protein to ruminants in 1994 . These measures resulted in substantial suppression of BSE over the following years $^{11-13}$ (FIG. 7).

Following the identification of vCJD in $1996\left(\mathrm{REF}^{25}\right)$, plausibly linked to $\mathrm{BSE}^{123}$, there was a worldwide ban on British beef exportation ${ }^{124}$ along with a ban on feeding mammalian protein to farmed animals (1996 in the UK (REF. ${ }^{11}$ ), subsequently adopted by the EU in 2001 $\left(\right.$ REF. $\left.^{11}\right)$ ) and a ban on human consumption of cattle over 30 months old in the UK ${ }^{124,125}$. The British beef exportation bans were lifted a number of years later (2006 in the EU, 2020 in the USA) $)^{126-129}$. In the UK, $>184,000$ cases of BSE were identified during the epizootic ${ }^{12}$ and modelling estimates that the total number of cases was 1-3 million $^{11}$, with $>4$ million cattle slaughtered as part of the containment response ${ }^{130}$. Dietary exposure of the UK population to BSE is likely to have been widespread $^{131-134}$ and substantial population exposures occurred in nations importing British beef (both livestock and carcasses), in particular France ${ }^{135}$, the largest importer. Smaller domestic BSE epizootics were reported in $>20$ other countries, posing an additional means of exposure to non-UK citizens ${ }^{13}$. The incidence of BSE is now negligible; occasional cases continue to be reported but control measures are likely to prevent these animals from entering the human food chain ${ }^{136,137}$. The connection between BSE and vCJD was made on the basis of epidemiological evidence that $\mathrm{vCJD}$ cases were linked to geographical areas with BSE exposure risk, the observation of parallel epidemic trajectories several years apart (FIG. 7), and a series of transmission experiments and neuropathological studies that provided evidence that BSE and VCJD are caused by the same strain of prion protein $^{123,138-140}$.

Existing CJD surveillance programmes ${ }^{141}$ were upgraded and new programmes initiated in the early 

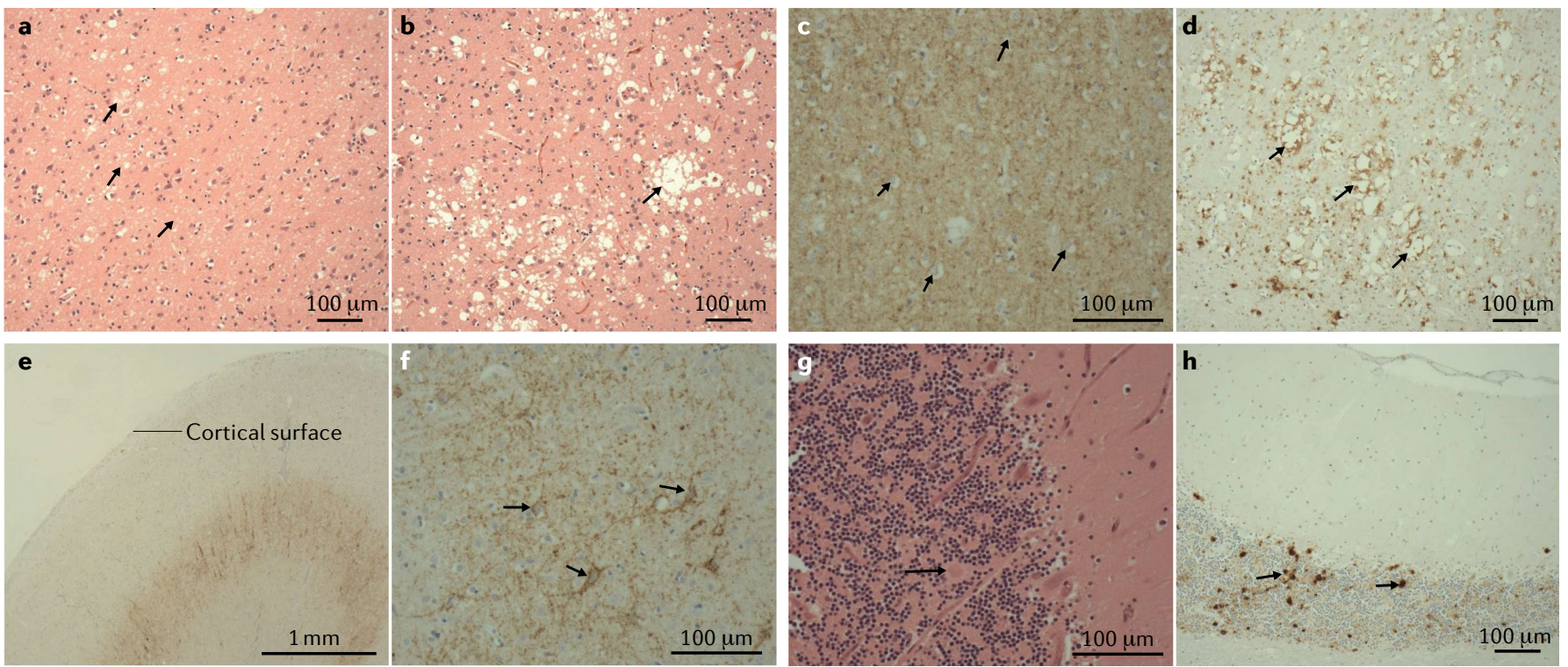

Fig. 3 | Histological features of sCJD. Histologically, the characteristic feature of prion diseases is spongiform change. Sporadic, genetic and acquired forms of prion disease show different patterns of spongiform change and, in individuals with sporadic Creutzfeldt-Jakob disease (sCJD), PRNP codon 129 genotype and western blot typing of the abnormal prion protein $(\mathrm{PrP})$ also influence the pattern of histological change. In this figure, we provide examples of the histology typically observed in the different forms SCJD. Frontal cortex section from an individual with the MM1 subtype of $\mathrm{SCJD}$ showing the fine cortical vacuolation (arrows) that is common in most prion disorders (HEE staining, $\times 100$ magnification) (part a). Frontal cortex section from an individual with the MM2 subtype of $\mathrm{sCJD}$ showing that fine vacuoles can coalesce to form coarse vacuoles (arrow), a feature particularly prominent in this subtype of sCJD (HEE staining, $x 100$ magnification) (part b). Frontal cortex section from an individual with the

MM1 subtype of sCJD showing a predominantly fine synaptic pattern of $\operatorname{Pr} P$ antibody staining (brown) counterstained with haematoxylin to visualize cell nuclei (blue; $\times 200$ magnification) (part c). Frontal cortex section from an individual with the MM2 subtype of sCJD showing coarser PrP antibody staining (brown) that is accentuated around the coalesced vacuoles (arrows; x100 magnification) (part d). Frontal cortex section from an individual with the $\mathrm{VV} 2$ subtype of SCJD showing a linear pattern of PrP antibody staining in the deeper cortex ( $\times 20$ magnification) (part e). A higher magnification image of the same sample shows that the staining in part $\mathbf{e}$ is peri-neuronal (frontal cortex section, $\mathrm{x} 200$ magnification) (part f). Cerebellar cortex section from an individual with the MV2 subtype of sCJD, showing kuru-like plaques (arrow; HEE staining, $x 400$ magnification) (part g). These plaques (arrows) are easily visualized with $\operatorname{PrP}$ antibody staining (brown; cerebellum, x100 magnification) (part h).

1990s following concerns over the potential for BSE transmission to humans ${ }^{29,30,142,143}$. With the identification of the first cases of VCJD in 1996 (REFS ${ }^{25,26}$ ), many additional nations developed and upgraded CJD surveillance programmes $^{144,145}$, leading to international cooperation, for example via the European Creutzfeldt-Jakob Disease Surveillance Network, which is funded by the European Centre for Disease Prevention and Control. International collaboration characterized the global vCJD epidemic ${ }^{10}$, which was centred in the UK. France experienced the second highest incidence of vCJD, which was thought to be largely as a result of the consumption of beef imported from the UK ${ }^{135,146}$. Spain had the third highest number of vCJD cases (five), three of which arose in a region with substantial rates of BSE in farmed cattle ${ }^{147}$. vCJD was also detected in nations that did not import British beef or have substantial rates of BSE, including Japan and the USA, and arose in individuals who had either spent time in the UK or in nations that imported British beef (such as Saudi Arabia) ${ }^{148}$. One individual in the USA was found to have vCJD in 2015 and had not spent time in the UK; this individual was thought to have been exposed prior to emigration to the US, presumably while living in Kuwait or Russia, nations known to have imported British beef ${ }^{27}$. This finding demonstrates that vCJD can arise across a broad geographical area.

\section{Ongoing public health concerns vCJD}

Extended incubation. Until 2016, all individuals with vCJD who underwent PRNP sequencing were found to have the MM c129 genotype ${ }^{108}$. One individual with vCJD and the MV genotype was identified in 2016 and was described in a paper by Mok et al. ${ }^{20}$, published in 2017. This individual presented at 35 years of age with personality change, later developing cognitive impairment, ataxia and myoclonus. MRI showed abnormal diffusion restriction in the basal ganglia, compatible with SCJD; medial thalamic changes were present but pulvinar nuclei were normal. CSF 14-3-3 protein levels were within the normal range and RT-QuIC produced a negative result. The total duration of disease from symptom onset to death was 16 months. Post mortem neuropathological analysis confirmed a diagnosis of vCJD. This was the first individual with the c129 MV genotype to have an autopsy-confirmed diagnosis of vCJD. However, another case of an individual with the MV genotype and suspected vCJD (on the basis of clinical and radiological evidence) was reported in 2009; autopsy of this individual was not performed ${ }^{149}$.

The Mok et al. case study ${ }^{20}$ added to growing concerns extrapolated from findings in $\mathrm{iCJD}^{5}$ and $\mathrm{Kuru}^{9}$ that prion disease transmission might be associated 
with extensive incubation (multiple decades) in individuals with non-MM c129 genotypes, adding weight to ongoing concerns of a 'second wave' of individuals developing vCJD. The exact incubation period of primary vCJD is impossible to calculate given the unknown timing of causative dietary exposure in affected individuals. The UK BSE epizootic was first detected in 1986 $\left(\right.$ REF. $\left.{ }^{150}\right)$, peaked in 1992 and fell to negligible numbers by the mid-2000s $\mathrm{s}^{12}$; human exposure to BSE is likely to have been minimal after 1996 following the stringent control measures described above ${ }^{11,124}$. All confirmed cases of vCJD prior to 2016 were seen in MM individuals, with global vCJD deaths peaking in 2000 (REF. ${ }^{10}$ ). The individual described in the study by Mok et al. ${ }^{20}$ did not fulfil the diagnostic criteria for vCJD during life but did fulfil those for SCJD. This observation raises the concern that, in non-MM individuals, the disease might present with different demographic, clinical, radiological, biochemical and neuropathological features to the classical vCJD phenotype, analogous to the effect of c129 genotype on sCJD phenotypes ${ }^{17,151-154}$. Such phenotypic variation could make it difficult to detect vCJD and distinguish it from $\mathrm{SCJD}$ on the basis of previously validated diagnostic criteria ${ }^{110}$ (BOX 2).

The individual in the Mok et al. ${ }^{20}$ study was considerably younger than is typical for individuals with sCJD. However, age might lack discriminatory value, as the paradigm that vCJD patients are typically younger than those with sCJD becomes increasingly flawed as time goes on - the BSE epizootic peaked in 1992 and 21 years

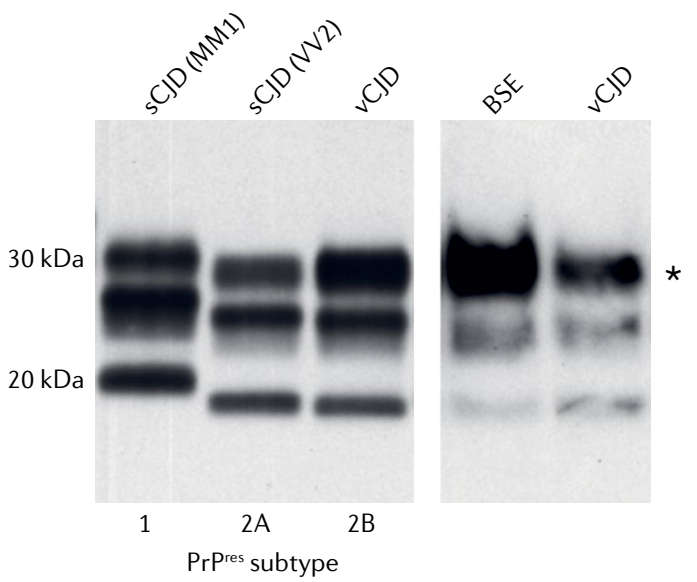

Fig. 4 | Western blot typing in CJD. Samples of brain tissue from individuals with Creutzfeldt-Jakob disease (CJD) can be treated with proteinase K before western blotting to detect protease-resistant fragments of misfolded prion protein (PrPres). PrPres is classified according to the molecular weight of the unglycosylated fragment, which is $21 \mathrm{kDa}$ in type $1 \mathrm{PrPres}^{\mathrm{r}}$ and $19 \mathrm{kDa}$ in type $2 \mathrm{PrPres}$. Type 2 is further classified into type $2 \mathrm{~A}$ and $2 \mathrm{~B}$ (variant CJD (vCJD)). Type 2B, present in both vCJD and bovine spongiform encephalopathy (BSE), is characterized by a predominant diglycosylated band $\left({ }^{*}\right)$. Examples are shown from individuals with sporadic CJD (sCJD) MM1, sCJD VV2, vCJD and from a case with BSE. MM, homozygous for methionine at codon 12 of the gene encoding prion protein; VV, homozygous for valine at codon 129 of the gene encoding prion protein. have passed since the peak of the first wave of vCJD in 2000. If the final year for potential dietary BSE exposure is 1996 , as is generally accepted, then, by definition, the youngest individuals to develop primary vCJD in 2021 would be 25 years old and must have been exposed early in life at the tail-end of the period of BSE exposure. The trends in vCJD incidence by birth cohort suggest that the highest vCJD risk follows exposure to BSE during youth and teenage years, with lower susceptibility in the very young ${ }^{155}$. No individuals born after 1990 have been diagnosed with vCJD in the $\mathrm{UK}^{155}$. The highest incidence of vCJD was seen in individuals born before 1980 and this is the population estimated to have received the largest dietary exposure to $\mathrm{BSE}^{134}$. Individuals born before 1980 will now be $>40$ years of age, substantially older than the individuals who comprised the first wave of vCJD infections (median age at onset 26.5 years) and overlapping with the age distribution seen in SCJD (median age at onset 67 years) ${ }^{1}$.

Although the scale of a potential second wave of vCJD is uncertain, extensive incubation in $\mathrm{Kuru}^{156}$ and $\mathrm{iCJD}^{108}$ is uncommon, which might partly reflect the lower attack rate in individuals with less susceptible c129 genotypes (generally MV ${ }^{5,9,15}$ ). This factor, in combination with extensive incubation periods, might lead to a more insidious incidence of new cases than was encountered in the most susceptible groups. Furthermore, prion diseases transmit more readily between individuals of the same species than between individuals of different species ${ }^{157,158}$. This characteristic is reflected in the significantly lower attack rate seen in primary vCJD secondary to BSE exposure (232 cases of vCJD worldwide ${ }^{10}$ despite widespread exposure in BSE-affected regions ${ }^{11,135}$ ) than in $\mathrm{iCJD}^{5,104}$ and $\mathrm{Kuru}^{9,94}$ (transmitted from human to human) and in the detection of several transfusion-mediated vCJD transmission events ${ }^{159,160}$. However, even with a low attack rate, the potential exists for further cases of vCJD, given the extensive BSE exposure in the UK and in other nations through domestic BSE cases and imports of cattle and beef products.

\section{Peripheral distribution of PrPsc}

In contrast to $S C J D$, in $\boldsymbol{v C J D}, \operatorname{PrP}^{\mathrm{sc}}$ is widely distributed in the lymphoreticular system ${ }^{161-163}$. This peripheral distribution is associated with substantial public health concerns related to iatrogenic transmission through transfusion and surgical procedures. Evidence exists to support the hypothesis that vCJD is acquired through the gut, with gradual spread to the CNS via the lymphoreticular system ${ }^{164}$. A series of immunohistochemical studies have demonstrated prevalent $\mathrm{PrP}^{\mathrm{Sc}}$ deposition in appendectomy samples from individuals in the $\mathrm{UK}^{165-167}$ (TABLE 1). Whether or not these individuals represent pre-clinical cases of vCJD and whether they pose a risk to public health through secondary transmission via surgical or medical procedures, blood products and organ donation is not yet clear ${ }^{165-167}$. In the initial study, published in 2004, researchers obtained samples from 14,964 appendectomies and 1,739 tonsillectomies and detected $\mathrm{PrP}^{\mathrm{Sc}}$ in three appendices, giving an estimated prevalence of 1 in 4,000 (REF. ${ }^{165}$ ). In a subsequent study, 


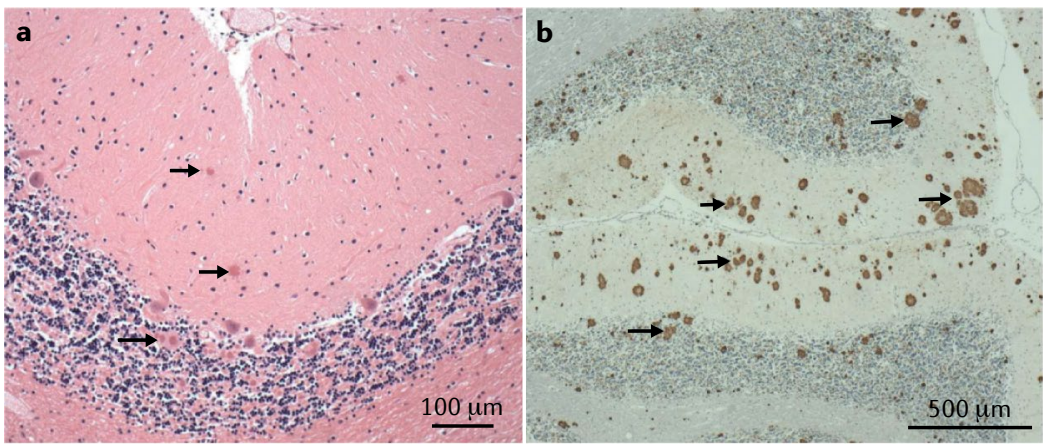

Fig. 5 | Histological features of genetic forms of prion diseases. Genetic forms of prion diseases show variable histological features and can resemble sporadic Creutzfeldt-Jakob disease; however, some show unique patterns of pathology. Image of a cerebellar section of an individual with the PRNP P102L-129M variant (the most common haplotype) of Gerstmann-Straussler-Scheinker disease showing multicentric plaques (arrows), which are most numerous in the molecular layer and granule cell layer (HEE staining, $\times 200$ magnification) (part a). A lower-magnification image from the same individual as in part a showing plaques (arrows) stained with prion protein antibody (brown; x40 magnification) (part b).

published in 2013, $\operatorname{PrP}^{\mathrm{sc}}$ was detected in 16 appendices from a sample of 32,441 specimens, yielding an estimated prevalence of 1 in 2,000 (REF. ${ }^{166}$ ). The most recent appendectomy study ${ }^{167}$, published in 2020 , aimed to measure the prevalence of $\mathrm{PrP}^{\mathrm{Sc}}$ in groups not thought to have been exposed to BSE and thus analysed samples from individuals who either had their appendix removed before $1980(n=14,692)$, the estimated beginning of the BSE period, or were born after $1996(n=14,824)$, the year from which the exposure risk is presumed to have reduced to a minimum. $\mathrm{PrP}^{\mathrm{Sc}}$ was detectable in the appendices of participants in both groups and the estimated prevalence ( 1 in 4,200) was not significantly different from that estimated in the above-mentioned 2013 study of a BSE-exposed population ${ }^{166,167}$. In the most recent study, the samples containing $\mathrm{PrP}^{\mathrm{Sc}}$ were obtained from patients who underwent appendectomy, or were born, close to the margins of the presumed 'at risk' period, raising concerns that the time-window of exposure to BSE might have commenced in the late 1970s and continued beyond 1996 (REF. ${ }^{167}$ ), which is a longer period than previously recognized.

Some cautionary notes regarding the appendectomy findings are necessary. First, the confidence intervals on the prevalence estimates are wide, making it difficult to estimate the extent of a possible epidemic relating to ongoing transmission. Second, Clewley et al. analysed 63,007 tonsil specimens from the UK obtained between 2004 and 2008 and did not find $\mathrm{PrP}^{\mathrm{Sc}}$ in any specimen, including in the 32,661 samples obtained from individuals born prior to $1996\left(\mathrm{REF}^{168}\right)$. Given that the detection of $\mathrm{PrP}^{\mathrm{Sc}}$ in tonsil is a highly sensitive diagnostic marker of vCJD - Hill et al. ${ }^{169}$ found detectable $\mathrm{PrP}^{\mathrm{Sc}}$ in $100 \%$ of tonsil biopsy samples from vCJD-affected individuals and in $0 \%$ of individuals in groups with other CJD subtypes or alternative neurological conditions - this result seems surprising. However, the stage at which tonsillar involvement arises in vCJD is unknown ${ }^{169}$. In the study by Hill et al. ${ }^{169}$, all patients with vCJD had clinically advanced disease and, to our knowledge, there are no published reports assessing tonsillectomy specimens obtained at pre-clinical or early clinical stages in individuals who died of vCJD. In addition, most individuals that undergo tonsillectomy are young; in the study by Clewley et al. ${ }^{168}$, 50,254 samples (79.7\%) were obtained from patients born after 1986. The oldest members of this cohort would have been 22 years of age in 2008 , the conclusion of the study period, so samples might have been resected before the disease reached this tissue. Last, the implications of the presence of $\mathrm{PrP}^{\mathrm{Sc}}$ in the appendix are unclear. One possibility is that $\mathrm{PrP}^{\mathrm{Sc}}$ in the appendix reflects dietary exposure to BSE-associated $\mathrm{PrP}^{\mathrm{Sc}}$, but that only a small proportion of exposed individuals develop vCJD, perhaps influenced by factors such as age, gut maturity, c129 genotype and the total amount of BSE-contaminated material ingested. The factors that influence BSE transmission to humans remain a topic of debate, particularly as individuals living in the same household as an individual with vCJD, sharing a common environment and meals, have not been found to develop the disease. One exception was a mother and son in Spain who both developed vCJD; however, these individuals were from the region with the highest vCJD incidence in the country and are thought to have had dietary exposure to high-risk material ${ }^{147}$. The transmissibility risk in individuals with appendicular $\operatorname{PrP}^{\mathrm{Sc}}$ is unknown. As the appendectomy studies ${ }^{165-167}$ were irreversibly anonymized, no participants were notified of being at-risk of CJD, a status that would carry numerous public health implications.

\section{Blood products and transplantation}

Three individuals in the UK were identified as having neuropathologically and biochemically confirmed vCJD related to the transfusion of non-leucodepleted red cells ${ }^{115,159,160,170,171}$. In addition, a case report by Peden et al. ${ }^{172}$ described an individual who received a blood transfusion from a donor and subsequently died of a non-neurological illness. This individual was found to have $\operatorname{Pr}^{\mathrm{Sc}}$ in the spleen but not in the brain, suggesting subclinical infection via the donor, who was known to have developed vCJD ${ }^{172}$. The blood products given to these individuals were obtained from donors before clinical manifestation of vCJD and were transfused before the introduction of leucodepletion for all blood products in 1999 (REFS ${ }^{159,173}$ ); no transfusion-transmitted cases of vCJD have occurred since this measure was introduced. Splenic $\mathrm{PrP}^{\mathrm{Sc}}$ was identified at autopsy in an individual with haemophilia who was asymptomatic for neurological disease $\mathrm{e}^{174}$. In this instance, $\mathrm{PrP}^{\mathrm{Sc}}$ is thought to have been transmitted through pooled plasma products known to have included a donor with pre-clinical vCJD. Animal studies have demonstrated that vCJD and BSE can be transmitted via the transfusion of blood products ${ }^{175,176}$. In addition, spleen inoculum from the individual described in the report by Peden et al. ${ }^{172}$ was shown to transmit vCJD to mice ${ }^{177}$. This observation provides further evidence that individuals with pre-clinical vCJD harbour the potential for transmission.

Epidemiological modelling studies have produced a wide range of estimates of the extent and duration of a potential secondary transmission epidemic of vCJD 
in the UK ${ }^{178-181}$. These studies addressed the potential effect of variables, including incubation time, infectivity, c129 genotype and probability of developing subclinical carrier status, and the effectiveness of interventions such as leucodepletion and donation restrictions. One study concluded that a self-sustaining secondary epidemic was possible, although biologically implausible $e^{178}$. A detailed review of these studies is beyond the scope of this article but noteworthy are the results of the most recent modelling study, which was published in 2019 and predicted lower numbers of transfusion-associated vCJD cases than previous studies ${ }^{180}$. A particular challenge is estimating the number of individuals with sub-clinical vCJD from transfusion and the resulting risk of ongoing transmission.

International studies matching donor and recipient pairs have not identified the transfusion-mediated transmission of non-variant forms of CJD ${ }^{160,182,183}$. Case-control studies have provided conflicting evidence over whether blood products pose a risk of non-variant forms of CJD ${ }^{184,185}$, although the results of an Italian study using a prolonged look-back period suggested an association between blood transfusion and increased risk of these forms of the disease ${ }^{53}$. The prolonged incubation of prion diseases as well as

\section{Box 2 | Diagnostic criteria for vCJD}

\section{Possible features:}

1. A. Progressive neuropsychiatric disorder

B. Duration of illness $>6$ months

C. Routine investigations do not suggest an alternative diagnosis

D. No history of potential iatrogenic exposure

E. No evidence of a familial form of transmissible spongiform encephalopathy

2. A. Early psychiatric symptoms ${ }^{a}$

B. Persistent painful sensory symptoms ${ }^{\mathrm{b}}$

C. Ataxia

D. Myoclonus or chorea or dystonia

E. Dementia

3. A. EEG does not show the typical appearance of sporadic Creutzfeldt-Jakob disease $(C J D)^{c}$ in the early stages of illness

B. Bilateral pulvinar high signal on MRI scan

4. A. Positive tonsil biopsy ${ }^{d}$

Diagnoses:

Definite vCJD

$1 \mathrm{~A}$ and neuropathological confirmation of $\mathrm{VCJD}$

\section{Probable vCJD}

1. 1 , four to five of $2,3 \mathrm{~A}$ and $3 \mathrm{~B}$

2. 1 and $4 a^{d}$

Possible vCJD

1 , four to five of 2 , and $3 \mathrm{~A}$

sCJD, sporadic CJD; vCJD, variant CJD. ${ }^{a}$ Depression, anxiety, apathy, withdrawal,

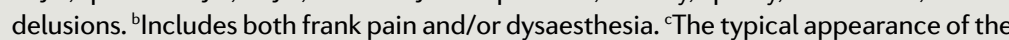
EEG in SCJD consists of generalized triphasic periodic complexes at approximately one per second. These may occasionally be seen in the late stages of $\mathrm{vCJD}$. ${ }^{\mathrm{d}}$ Tonsil biopsy is not recommended routinely nor in cases with EEG appearances typical of sCJD but might be useful in suspect cases in which the clinical features are compatible with vCJD

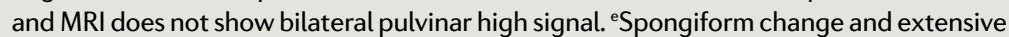
prion protein deposition with florid plaques throughout the cerebrum and cerebellum. Adapted from REF. ${ }^{269}$, CC BY 4.0 (https://creativecommons.org/licenses/by/4.0/). difficulties in working with records and the potential for various forms of bias, pose challenges for epidemiological studies. Recipients of transfusion might die before manifesting CJD or disease manifestations could be obscured by the comorbid illnesses that necessitated transfusion. In 2017, a case report described two individuals who received UK-derived plasma products and died of autopsy-confirmed MM1-subtype sCJD ${ }^{186}$. This observation raises concerns but does not conclusively demonstrate causality.

Measures to mitigate the risk of blood productassociated $\mathrm{CJD}^{72,187}$ include leucoreduction, a ban on blood donations by previous transfusion recipients and individuals deemed to be at-risk of CJD, and restrictions on transfusing UK-derived plasma to UK residents born after 1996. The latter restrictions, which mandated the importation of plasma for UK use, were withdrawn in 2019 following a revised risk assessment that demonstrated a low probability of further vCJD deaths arising from plasma exposure ${ }^{187}$. In many nations, individuals who lived in BSE-exposed regions during the epizootic cannot donate blood; however, restrictions in the USA were partially lifted in 2020 , partly owing to limitations in the blood supply related to the COVID-19 pandemic ${ }^{72}$. No validated means of testing donors for preclinical vCJD currently exists; such an assay would be invaluable. Protein misfolding cyclic amplification (PMCA) is a highly sensitive and specific diagnostic test for vCJD ${ }^{188,189}$ and can identify preclinical vCJD in blood ${ }^{189}$, although this finding needs to be replicated in larger cohorts before PMCA can be validated for screening purposes. Furthermore, PMCA has practical limitations as the process amplifies $\operatorname{PrP}^{\mathrm{Sc}}$, generating an infectious agent with substantial biohazard potential ${ }^{190-192}$. PMCA results also require time to process, which might be longer than the shelf-life of blood products, limiting utility as a screening test for blood donation. A successful screening test for vCJD would generate additional challenges, including the ethical considerations involved in notifying donors that they have possible preclinical vCJD but that their risk of developing this lethal disease is uncertain.

\section{Potential for laboratory transmission}

Strict occupational health measures govern all clinical and research activities concerning prion disease tissue samples ${ }^{193}$. Two laboratory workers who had worked with prion disease samples are known to have died from $\mathrm{vCJD}^{16}$. One individual, described in a case report by Brandel et al., had a clear history of a penetrating skin injury from an instrument used to handle BSE material 7.5 years before diagnosis ${ }^{16}$. This individual had a typical prodromal thalamic pain syndrome and neuropsychiatric features as well as a typical MRI with pulvinar and dorsomedial thalamic hyperintensities. RT-QuIC analysis of CSF was negative, PMCA of plasma and CSF was positive, and a definitive diagnosis of VCJD was provided post mortem. The individual had an MM c129 genotype. The interval between injury and clinical onset was consistent with the incubation period observed in individuals with transfusion-transmitted vCJD, suggesting that this injury was the vector for disease transmission as opposed to primary infection through the diet. 
An Italian lab worker who had worked with BSE and vCJD brain material died of vCJD in $2016\left(\right.$ REF. $\left.^{16}\right)$. In contrast to the individual described by Brandel et al. ${ }^{16}$, this individual had no history of accidental injury. Evidence exists that scrapie can be transmitted through scarification of the skin, adding to concerns of peripheral transmission of $\mathrm{vCJD}^{16}$. The potential for occupational exposure remains an important means of $\mathrm{vCJD}$ transmission.

\section{sCJD and iCJD}

Peripheral pathogenesis and iatrogenic transmission. Evidence of peripheral pathogenesis in SCJD is increasing ${ }^{194,195}$. Studies have now identified $\mathrm{PrP}^{\mathrm{Sc}}$ in retinal and optic nerve tissue ${ }^{196,197}$, although at concentrations lower than those found in the brain. $\mathrm{PrP}^{\mathrm{Sc}}$ has also been detected in intracranial portions of the vagus nerve, but extracranial portions have not been tested ${ }^{198}$. A recent study ${ }^{194}$ demonstrated detectable $\mathrm{PrP}^{\mathrm{Sc}}$ in a range of peripheral tissues including skin and femoral nerve. The advent of amplification techniques, including RT-QuIC, has enabled the detection of $\mathrm{PrP}^{\mathrm{Sc}}$ in peripheral tissues at concentrations below the threshold for detection by the traditional methods of immunohistochemistry and western blot analysis ${ }^{199,200}$. RT-QuIC is now a validated test for the diagnosis of sCJD from CSF and olfactory mucosal brushings ${ }^{64}$. RT-QuIC has detected $\mathrm{PrP}^{\mathrm{Sc}}$ in the skin of individuals with sCJD and $\mathrm{gCJD}$; $\mathrm{PrP}^{\mathrm{Sc}}$ levels increased with disease duration ${ }^{200}$. Whether such levels of $\mathrm{PrP}^{\mathrm{Sc}}$ are sufficient for transmission via surgical instruments is unclear. However, one study found that bone marrow from individuals with sCJD contains $\mathrm{PrP}^{\mathrm{Sc}}$ that can be transmitted to transgenic mice expressing human $P R N P^{201}$, adding to concerns around potential transfusion-mediated transmission as blood cells arise from haematopoietic progenitor cells in the bone marrow.

Some case-control studies have identified an association between surgery, including abdominal procedures, and SCJD; however, these studies face similar challenges to those used to study blood transfusion, including the need for prolonged look-back periods and the potential for bias ${ }^{51,52,202}$. Evidence indicates that iCJD resulting from the peripheral injection of contaminated c-hGH has a substantially longer incubation period (mean 17 years) than iCJD resulting from neurosurgical instrument-mediated transmission (1.4 years for neurosurgical instruments, 1.3 years for stereotactic EEG needles and 12 years for hDM grafting ${ }^{15}$. This observation suggests that the hypothetical iatrogenic transmission of CJD via non-CNS and non-ophthalmologic surgical and medical procedures could be associated with decades-long incubation. One study found that intracerebral inoculation with vCJD prion-contaminated steel wires can transmit vCJD to mice even when the wires have been subjected to conventional prion decontamination measures, including the use of sodium hypochlorite, sodium hydroxide and steam sterilization at $134^{\circ} \mathrm{C}$ $\left(\mathrm{REF}^{203}\right)$. This finding raises concerns over the effectiveness of these procedures in sterilizing medical equipment. Unfortunately, tracing patients who have been exposed to shared instruments is more challenging than tracing the origin of blood products.

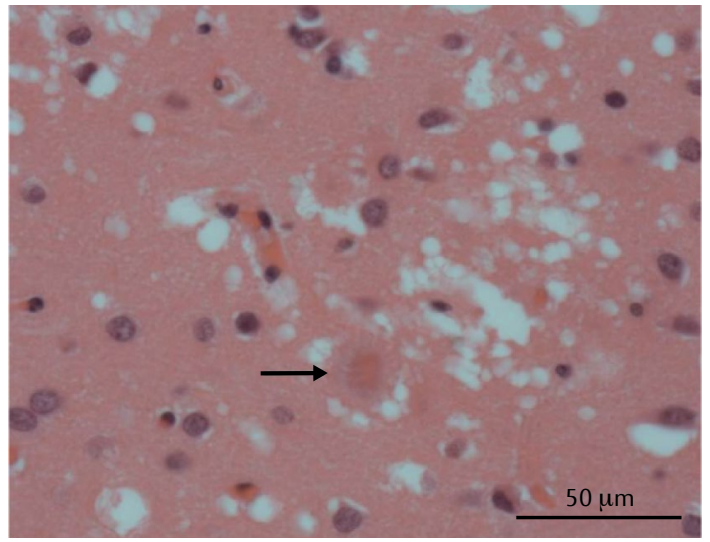

Fig. 6 | Histological features of vCJD. Frontal cortex section from an individual with variant Creutzfeldt-Jakob disease (vCJD) showing a pathognomonic florid plaque (arrow), a fibrillar amyloid plaque surrounded by vacuolation (H\&E staining, x400 magnification).

The urine of individuals with SCJD was not found to be infective when intracerebrally administered to mice ${ }^{204}$; however, small quantities of $\mathrm{PrP}^{\mathrm{Sc}}$ have been detected in the urine of individuals with vCJD using $\mathrm{PMCA}^{205}$. The authors of one study raised concern about the safety of urine-derived human gonadotrophins following the detection of prion protein in samples ${ }^{206}$, but no evidence exists that recipients of urine-derived hormones are at increased risk of developing CJD. Whether $\mathrm{PrP}^{\mathrm{Sc}} \mathrm{can}$ be detected in the urine of individuals with preclinical vCJD and whether this $\mathrm{PrP}^{\mathrm{Sc}}$ is present in sufficient quantities to enable transmission are not yet known.

Some studies assessing occupational risk have identified a possible increased incidence of sCJD among health-care workers compared with the general population $^{202,207,208}$, although other studies have produced conflicting results ${ }^{202,207,209}$. A retrospective cohort study published in 2020 identified an increased incidence of sCJD among medical professionals in Germany compared with the general population ${ }^{210}$; the risk was highest among surgeons. These observations raise concerns over the potential for substantial occupational exposure with decades-long incubation. However, caution is advised in the interpretation of these occupational risk studies as there is potential for methodological biases to influence the results. For example, medical professionals have a heightened understanding and recognition of sCJD and epidemiological survey data on occupation is more complete in this group of individuals than in some other groups. The inherent limitations of case-control studies, such as the potential for recall bias, the effects of confounding variables and the inability to conclusively demonstrate a causal relationship ${ }^{211}$, should also be considered.

The rising incidence of $s C J D$. $\mathrm{sCJD}$ has been identified in many geographical regions ${ }^{2}$. In nations with sophisticated surveillance programmes, including the $\mathrm{UK}^{1}$, France ${ }^{2}$, Germany ${ }^{30}$, Australia ${ }^{47}$, Canada ${ }^{212}$ and the USA ${ }^{31}$, the numbers of reported cases of sCJD have 


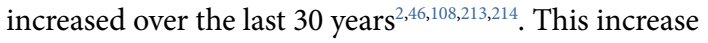
is likely to be the result of a combination of factors, including better case ascertainment with heightened awareness, recognition of atypical phenotypes, the availability of more sensitive tests ${ }^{215}$ and revised diagnostic criteria $^{57}$, and population growth and ageing owing to advances in medicine and public health. Currently unknown exogenous risk factors could also theoretically account for some of the observed increase in incidence of sCJD. Besides iatrogenic transmission, no evidence exists of person-to-person transmission of sCJD or $\mathrm{vCJD}^{216}$. Geographical clustering of individuals with SCJD has been described ${ }^{217}$, but the data do not support the existence of local point-source outbreaks or personto-person transmission of the disease. Heightened local surveillance following reported cases could be one factor underlying spatial clustering ${ }^{218}$.

The observed increasing incidence of sCJD underscores the importance of the public health concerns described in this article. A national approach to CJD surveillance facilitates cooperation with national blood services and public health agencies, which is necessary for tracing exposed individuals and mitigating risk. In several nations, large-scale look-back studies are performed in conjunction with surveillance ${ }^{160,182,183}$ and are essential in identifying possible cases as well as in managing risk in exposed individuals. In summary, the increasing incidence of sCJD requires careful longitudinal evaluation in a manner that can only be achieved by systematic surveillance programmes.

\section{Prion diseases with zoonotic potential}

Chronic wasting disease. Chronic wasting disease (CWD) of cervids was first recorded in a captive deer in Colorado, USA, in 1969 and was classified as a spongiform encephalopathy on histological examination of brain tissue in $1978\left(\right.$ REF. $\left.^{219}\right)$. Eight cervid species are susceptible to CWD; the disease was detected in five of these in natural conditions and the remaining three are susceptible to experimental transmission ${ }^{219}$. CWD has been detected in 26 states in the USA, in 3 Canadian provinces, and in Norway, Finland, Sweden and South Korea (the cases in South Korea were as a result of the transport of infected live animals) ${ }^{14,220}$. CWD was detected in a wild reindeer in Norway in 2020, highlighting the ongoing risk of CWD transmission ${ }^{221}$. In contrast to BSE, CWD emerges in free-ranging cervids, although the effect of animal husbandry, feeding and agricultural practices contributes to disease propagation ${ }^{220}$. In animals with $\mathrm{CWD}, \mathrm{PrP}^{\mathrm{Sc}}$ is easily shed into the environment through various secretions and excretions, including saliva ${ }^{222}$, urine ${ }^{223}$ and faeces ${ }^{224,225}$, can survive in soil for prolonged periods ${ }^{226,227}$, and is resistant to environmental challenges such as freeze-thaw cycles $^{225,228}$. CWD is horizontally transmitted between living animals $^{222}$ and through environmental exposure to $\operatorname{PrP}^{\mathrm{Sc}}$ $\left(\mathrm{REF}^{227}\right)$. Carcasses are a vector and new animals entering a previously inhabited field can contract the disease, possibly through the consumption of plants growing at the site of carcasses as well as through the soil ${ }^{226}$. $\mathrm{PrP}^{\mathrm{Sc}}$ is detectable in the flesh of infected animals ${ }^{229}$, raising the concern that dietary transmission to humans could be possible.

No proven instances of CWD-associated human prion disease have been reported. Evidence indicates that CWD can be transmitted via intracerebral inoculation to multiple non-cervid species ${ }^{230-235}$ as well as via oral or intracerebral exposure to squirrel monkeys ${ }^{236}$. However, evidence indicates that CWD is not transmissible by either route to cynomolgus macaques, which are a primate species genetically closer to humans than to squirrel monkeys ${ }^{237}$. Humanized transgenic mice expressing human $P R N P$ are resistant to CWD infection, whereas transgenic mice expressing cervid PRNP are $\operatorname{not}^{238}$. However, in one study, CWD brain isolates were able to induce the misfolding of human $\operatorname{PrP}^{\mathrm{C}}$ in vitro ${ }^{239}$. In another study, transgenic mice expressing a form of human prion protein that overlaps with elk prion protein

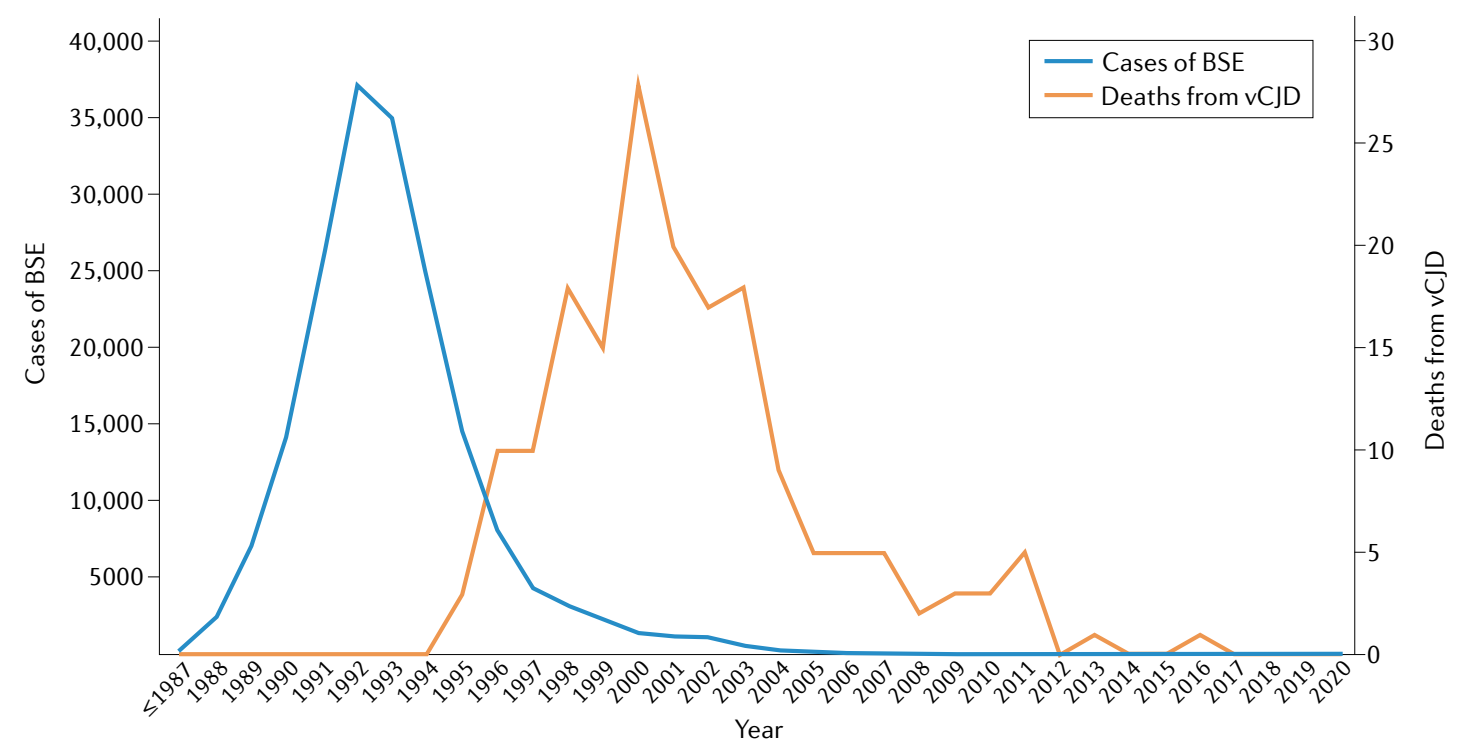

Fig. 7 | BSE and vCJD in the UK. Graph shows the trajectory of the bovine spongiform encephalopathy (BSE) epizootic and the subsequent variant Creutzfeldt-Jakob disease (vCJD) epidemic in the UK. Data obtained from REFS ${ }^{12,288}$. 
Table 1 | Studies of PrPSc carriage in resected lymphoreticular tissues in the UK

\begin{tabular}{|c|c|c|c|}
\hline Study & Cohort information & $\begin{array}{l}\text { Number of } \\
\text { appendices with } \\
\text { detectable PrPsc }\end{array}$ & $\begin{array}{l}\text { Estimated } \\
\text { population } \\
\text { prevalence }\end{array}$ \\
\hline $\begin{array}{l}\text { Hilton et al. } \\
(2004)^{165}\end{array}$ & $\begin{array}{l}\text { Born in 1961-1985; operations } \\
\text { performed in 1995-1999: 14,964 } \\
\text { appendectomies and 1,739 } \\
\text { tonsillectomies }\end{array}$ & 3 & 1 in 4,000 \\
\hline $\begin{array}{l}\text { Gill et al. } \\
(2013)^{166}\end{array}$ & $\begin{array}{l}\text { Born in 1941-1985; operations } \\
\text { performed in 2000-2012: } 32,441 \\
\text { appendectomies }\end{array}$ & 16 & 1 in 2,000 \\
\hline \multirow[t]{2}{*}{$\begin{array}{l}\text { Gill et al. } \\
(2020)^{167}\end{array}$} & $\begin{array}{l}\text { Born in 1891-1965; operations } \\
\text { performed in 1962-1979: 14,692 } \\
\text { appendectomies }\end{array}$ & $2^{\mathrm{a}}$ & \multirow[t]{2}{*}{1 in $4,200^{c}$} \\
\hline & $\begin{array}{l}\text { Born after 1996; operations } \\
\text { performed in 2000-2014: 14,824 } \\
\text { appendectomies }\end{array}$ & $5^{b}$ & \\
\hline
\end{tabular}

at residues 165-175 were susceptible to CWD inoculation, providing information on the structural elements underlying the species barrier ${ }^{240}$.

One study followed up a cohort of individuals who had been exposed to CWD-contaminated products in 2005; no evidence of prion disease or other neurodegenerative diseases emerged between exposure and the end of follow-up in 2011 (REF. ${ }^{241}$ ). Given that the incubation period for some forms of acquired CJD can be decades long, surveillance must continue to ensure the identification of any individuals who develop CWD-associated human prion disease. How CWD-associated human prion disease might manifest is unknown and it could be challenging to distinguish the new disease from other forms of CJD. vCJD was first identified when the UK surveillance system detected a novel prion disease with previously unseen clinical, radiological, biochemical and neuropathological features ${ }^{25}$. Therefore, large-scale national surveillance programmes are necessary to identify novel diseases that might be linked to CWD as well as to provide registry data for case-control studies on exposure risks, to enable follow-up of exposed individuals through cohort registries and to facilitate international liaison with veterinary surveillance programmes.

Human exposure to CWD is highly likely. A survey of 17,372 US residents found that $67.4 \%$ of respondents had consumed venison, much of it obtained from the wild, and $18.5 \%$ of respondents reported hunting as a pastime ${ }^{242}$. Without large-scale testing, the proportion of animals infected with CWD is unknown; estimates vary widely ${ }^{243,244}$ by region, species and between captive versus wild animals, with one study demonstrating a prevalence of $35.4 \%$ among white-tailed deer in Wyoming ${ }^{245}$. At present, validated means of screening slaughtered animals for CWD to ensure safe dietary consumption are not widely employed and current methods are highly time consuming ${ }^{220}$. Furthermore, prions can adhere to steel surfaces ${ }^{246-248}$ and instruments used for the slaughter and butchery of cervids are frequently not subjected to validated decontamination measures ${ }^{220}$. Finally, concerns exist over the potential for altered transmissibility after passage through intermediate host species. This has been demonstrated in CWD, wherein passage through ferrets extends the range of susceptible host species ${ }^{249}$, as well as in transgenic mice expressing human or porcine $\mathrm{PrP}^{\mathrm{C}}$, which display an increased susceptibility to sheep-passaged BSE compared with non-sheep-passaged $\mathrm{BSE}^{250,251}$. In summary, although the zoonotic potential of CWD is unclear, the risk of human exposure is substantial.

Camel prion disease. A novel prion disease, termed camel prion disease (CPD), was detected in three symptomatic dromedary camels in Algeria in $2018\left(\mathrm{REF}^{252}\right)$. The $\mathrm{PrP}^{\mathrm{res}}$ signature of CPD did not match that of scrapie or $\mathrm{BSE}^{252}$, which raised several concerns. First, the disease was presumed to have arisen naturally; transmission of a prion disease from another species was not suspected, as no BSE had been detected in local cattle and naturally arising scrapie is not known to be present in Algeria $^{252}$. Second, camels were the first non-ruminant species, other than humans, to naturally manifest prion disease, thus extending the spectrum of prion diseasesusceptible animals ${ }^{252}$. Third, $\operatorname{PrP}^{\mathrm{Sc}}$ was detectable in peripheral lymphoid tissues, raising concern for horizontal transmission ${ }^{252}$. Last is the possibility that the causative agent could undergo alteration on passage through an intermediate host, enhancing transmissibility, as discussed above.

Another camel with CPD was identified in Tunisia in 2019 (REF. ${ }^{253}$ ). Concerns now exist over the prevalence of this previously unrecognized transmissible spongiform encephalopathy, and recognition of cases will likely increase as a result of heightened awareness ${ }^{254}$. The global dromedary population is in the millions, with large populations in Africa and the Middle East, as well as in Australia ${ }^{255,256}$. The potential for human exposure to CPD is substantial; however, transmission studies will be necessary to determine whether the disease has zoonotic potential. Substantial constraints on resources as well as geopolitical instability in the regions affected by CPD pose major challenges; many affected countries do not have national CJD surveillance programmes.

\section{Other protein-misfolding disorders}

Starting in 2010, emerging evidence has indicated that misfolded proteins in non-prion disease disorders, such as Alzheimer disease, cerebral amyloid angiopathy, Parkinson disease and motor neuron disease, could have prion-like characteristics, that is, protein-induced protein misfolding, cell-to-cell transmission and potential inter-subject transmissibility ${ }^{257-264}$. Amyloid- $\beta$ pathology has been detected in recipients of $\mathrm{c}-\mathrm{hGH}^{257,265}$, $\mathrm{hDM}$ grafting ${ }^{259}$ and childhood neurosurgery ${ }^{258}$, raising questions over the transmissibility of misfolded amyloid- $\beta$, which has been demonstrated in transgenic mice ${ }^{260,261}$. Evidence from preclinical studies and studies of recipients of fetal mesencephalic neuronal grafts suggests that a-synuclein can be induced to misfold in the presence of its misfolded form ${ }^{262}$. In mouse models, SOD1-linked motor neuron disease can be transmitted via the injection of spinal homogenates into the sciatic nerves ${ }^{263}$. Studies in transgenic mice have also demonstrated the 
transmissibility of tau pathology ${ }^{264}$. Taken together, these findings raise questions over whether other protein-misfolding disorders are transmissible between humans. However, the human studies mentioned above have small sample sizes and the public health implications of the potential transmissibility are still unclear. More evidence is required to establish whether these disorders harbour risks of transmission comparable to prion diseases.

\section{Wider benefits of surveillance Novel diagnostic strategies}

Our ability to diagnose of CJD during life has greatly improved over the last several decades thanks to advances in $\mathrm{MRI}^{58}$ and CSF biomarkers ${ }^{64,65,266}$. The current diagnostic criteria for sCJD were revised in 2017 (BOX 1) to include multifocal cortical ribboning on MRI and a positive RT-QuIC assay ${ }^{267-269}$. These revised criteria have a sensitivity of $97 \%$ and a specificity of $99 \%$

\begin{tabular}{l} 
Suspected CJD \\
Referral to surveillance centre \\
Specialist assessment \\
- Case records review \\
- Patient and relatives interview \\
- Examination \\
Risk factor assessment \\
- latrogenic exposure \\
- Family history \\
- Occupational and zoonotic exposure \\
Referral for ongoing care \\
Enrollment in trials \\
Optional genetic counselling and predictive PRNP \\
- Contact tracing to identify exposed individuals \\
Diagnostics \\
- MRI review by specialist \\
- CSF analysis (14-3-3, RT-QulC, +/- PMCA) \\
- EEG \\
PRNP sequencing (c129 and mutation sequencing) \\
Consider autopsy \\
Puantining of instruments and blood products \\
\hline
\end{tabular}

Fig. 8 | A model CJD surveillance system. A flowchart depicting a model system for comprehensive national Creutzfeldt-Jakob disease (CJD) surveillance, based on a combination of systems used in the authors' nations, is shown. This system provides a detailed diagnostic assessment including the ascertainment of the CJD subtype, screening for important epidemiological risk factors, and evaluating for and mitigating risks of transmission to others. CSF, cerebrospinal fluid; PMCA, protein misfolding cyclic amplification; RT-QulC, real-time quaking-induced conversion. (compared with previously used criteria that had a sensitivity of $74 \%$ and a specificity of $99 \%$ ) and are likely to have contributed to the rising incidence figures ${ }^{57}$.

The prompt and accurate diagnosis of CJD during life confers multiple benefits. First, it enables public health measures, such as quarantining of potentially contaminated blood products and medical instruments, to be swiftly enacted. Second, it allows a transition from ineffective and potentially harmful empirical therapies (for example, immunosuppression) and life-prolonging therapies that do not enhance quality of life ${ }^{270}$ to palliative care in an appropriate facility. Third, it can rapidly rule out the possibility of CJD in individuals with a mimicking condition, such as autoimmune encephalitis, leading to appropriate, potentially life-saving, treatment ${ }^{271}$. Last, rapid diagnosis is essential for the recruitment of participants for clinical trials.

\section{Clinical trials}

CJD is rare and, with the exception of individuals known to be at-risk owing to prior exposures or individuals with inherited mutations, new cases arise in an unpredictable manner with no geographical focus. The latency to diagnosis is often considerable and the duration of survival following diagnosis is typically short. Several of these factors present challenges to clinical trials in CJD: sample sizes are small and the window of time available to enrol patients in studies and to assess the benefit of interventions is short. To date, few randomized controlled trials have been conducted and no interventions have been found to improve outcomes for individuals with $\mathrm{CJD}^{272-278}$. However, multinational clinical trials in CJD are feasible ${ }^{273}$ and surveillance programmes are instrumental for rapid diagnoses and in coordinating the enrolment of patients in trials, with scope for multinational collaboration to bolster sample sizes. Rapid diagnosis is particularly essential as therapeutic agents shown to work in preclinical studies might not be effective when irreversible neurodegeneration has already occurred.

\section{Recommendations for ongoing surveillance}

CJD is likely to be under-recognized in nations that lack sophisticated surveillance systems. Several reports from low-income and middle-income nations have described challenges relating to the diagnosis of CJD, including financial constraints, lack of testing facilities, underdeveloped health-care infrastructure, low numbers of neurologists, and regional disparities between rural and urban centres ${ }^{36,38,48,49,279}$. Geopolitical instability along with the burden of COVID-19 and other communicable diseases will pose further challenges to the ascertainment of CJD in some of these nations. Consequently, substantial public health risks might arise. Nations with established surveillance systems should provide support to those that are developing their programmes. Existing systems range from low-fidelity services, such as the review of death certificates (known to have limitations and to underestimate CJD incidence ${ }^{31}$ ), through to high-fidelity systems that include mandatory reporting, direct clinical assessment, and integrated specialist neuroradiology, genetic, biochemistry and 
neuropathology facilities closely aligned to public health services $^{1,268}$. International collaboration enables the epidemiological comparison between nations as well as the enhanced recognition of atypical forms of prion disease.

A model surveillance system is shown in FIG. 8 and is a hybrid of the high-fidelity systems in place in the authors' nations. The clinical assessment of individuals with suspected CJD can include case record review, liaison between local neurologists and national centres, and the direct assessment of cases by national specialists, in-person or through telehealth ${ }^{280,281}$ (of particular utility during the COVID-19 pandemic ${ }^{282}$ ). Surveillance centres are well placed for integration with biomarker laboratories for rapid diagnostic services as well as for research into newer-generation non-invasive biochemical and imaging biomarkers ${ }^{200,283}$ for early diagnosis and screening ${ }^{284,285}$, and instrument decontamination testing ${ }^{286}$. Crucially, ongoing surveillance can enable the recruitment of participants for the therapeutic trials that might one day offer hope to people affected by this devastating group of diseases ${ }^{287}$.

\section{Conclusions}

With the potential for UK population exposure to BSE over a longer period than was previously assumed, evidence of prevalent carriage of VCJD material in the lymphoreticular systems of healthy individuals, and concerns around secondary transmission through blood products and surgery, vCJD remains a priority for surveillance in Europe. Increasing numbers of sporadic and inherited CJD cases are now being recognized globally and evidence of sCJD disease pathogenesis outside of the nervous system suggests the potential for iatrogenic transmission. Individuals who develop iCJD after extensive incubation periods are still being identified globally and the spectrum of inherited prion diseases is ever increasing. Additional concerns arise around potential zoonoses, such as CWD and CPD, and novel findings that suggest the potential transmissibility of other protein-misfolding disorders. Large-scale surveillance with international cooperation remains a priority in order to recognize atypical cases of prion disease in humans as well as to minimize population exposure risks. Finally, national surveillance programmes are uniquely placed to study this devastating family of diseases, improving diagnosis and symptomatic treatment with the aim of finding a cure. We advise that prion disease surveillance remains a public health priority, including when other priorities such as COVID-19 risk take precedent.

Published online 10 May 2021
1. National CJD Research \& Surveillance Unit. 28th Annual Report 2019. Creutzfeldt-Jakob Disease Surveillance in the UK https://www.cjd.ed.ac.uk/sites/ default/files/Report28.pdf (2020).

2. Uttley, L., Carroll, C., Wong, R., Hilton, D. A. \& Stevenson, M. Creutzfeldt-Jakob disease: a systematic review of global incidence, prevalence, infectivity, and incubation. Lancet Infect. Dis. 20, e2-e10 (2020).

3. Kovacs, G. G. et al. Genetic prion disease: the EUROCJD experience. Hum. Genet. 118, 166-174 (2005). An international study on the epidemiology of genetic prion diseases in the Euro-CJD network nations.

4. Masters, C. L. et al. Creutzfeldt-Jakob disease: patterns of worldwide occurrence and the significance of familial and sporadic clustering. Ann. Neurol. $\mathbf{5}$ 177-188 (1979).

5. Brown, P. et al. latrogenic Creutzfeldt-Jakob disease final assessment. Emerg. Infect. Dis. 18, 901-907 (2012).

A detailed summary of the iCJD epidemic worldwide.

6. Prusiner, S. B. Prions. Proc. Natl Acad. Sci. USA 95 13363-13383 (1998).

7. Nobel Media. The Nobel Prize in Physiology or Medicine 1997 https://www.nobelprize.org/prizes/ medicine/1997/summary (2020).

8. Gajdusek, D. C. \& Zigas, V. Kuru; clinical, pathological and epidemiological study of an acute progressive degenerative disease of the central nervous system among natives of the Eastern Highlands of New Guinea. Am. J. Med. 26, 442-469 (1959).

9. Collinge, J. et al. Kuru in the 21 st century-an acquired human prion disease with very long incubation periods. Lancet 367, 2068-2074 (2006). A surveillance report on Kuru, a disease associated with endocannibalism in Papua New Guinea, demonstrating extensive incubation lasting several decades associated with prion protein codon 129 polymorphism status.

10. National CJD Research \& Surveillance Unit. Variant CJD cases worldwide https://www.cjd.ed.ac.uk/ surveillance/data-and-reports (2020).

11. Smith, P. G. \& Bradley, R. Bovine spongiform encephalopathy (BSE) and its epidemiology. Br. Med. Bull. 66, 185-198 (2003).

12. World Organization for Animal Health. Number of cases of bovine spongiform encephalopathy (BSE) reported in the United Kingdom https://www.oie.int/en/ animal-health-in-the-world/bse-specific-data/numberof-cases-in-the-united-kingdom/ (2020).
13. World Organization for Animal Health. Number of reported cases of bovine spongiform encephalopathy (BSE) in farmed cattle worldwide (excluding the United Kingdom) https://www. oie.int/animal-health-in-theworld/bse-situation-in-the-world-and-annual-incidencerate/number-of-reported-cases-worldwideexcluding-the-united-kingdom/ (2020).

14. Centers for Disease Control and Prevention. Chronic Wasting Disease (CWD) https://www.cdc.gov/prions cwd/occurrence.html (2020).

15. Rudge, P. et al. latrogenic CJD due to pituitary-derived growth hormone with genetically determined incubation times of up to 40 years. Brain 138 , 3386-3399 (2015).

Case series demonstrating that human growth hormone-associated iCJD can incubate for several decades, influenced by prion protein gene codon 129 polymorphism status.

16. Brandel, J. P. et al. Variant Creutzfeldt-Jakob disease diagnosed 7.5 years after occupational exposure. N. Engl. J. Med. 383, 83-85 (2020).

17. Parchi, P. et al. Classification of sporadic CreutzfeldtJakob disease based on molecular and phenotypic analysis of 300 subjects. Ann. Neurol. 46, 224-233 (1999).

A large clinicopathological series on SCJD demonstrating the relationship between clinical features and the underlying genetics and neuropathology

18. Palmer, M. S., Dryden, A. J., Hughes, J. T. \& Collinge, J. Homozygous prion protein genotype predisposes to sporadic Creutzfeldt-Jakob disease. Nature 352 340-342 (1991)

19. Collinge, J., Palmer, M. S. \& Dryden, A. J. Genetic predisposition to iatrogenic Creutzfeldt-Jakob disease. Lancet 337, 1441-1442 (1991)

20. Mok, T. et al. Variant Creutzfeldt-Jakob disease in a patient with heterozygosity at PRNP Codon 129. N. Engl. J. Med. 376, 292-294 (2017). The first confirmed case of vCJD with prion protein gene codon 129 heterozygosity, a factor associated with prolonged incubation in other forms of acquired prion disease.

21. Chen, C. \& Dong, X. P. Epidemiological characteristics of human prion diseases. Infect. Dis. Poverty 5, 47 (2016).

22. Parchi, P. et al. Molecular basis of phenotypic variability in sporadic Creutzfeldt-Jakob disease. Ann. Neurol. 39, 767-778 (1996).

23. Head, M. W. et al. Prion protein heterogeneity in sporadic but not variant Creutzfeldt-Jakob disease:
UK cases 1991-2002. Ann. Neurol. 55, 851-859 (2004).

24. Tee, B. L., Longoria Ibarrola, E. M. \& Geschwind, M. D. Prion diseases. Neurol. Clin. 36, 865-897 (2018).

25. Will, R. G. et al. A new variant of Creutzfeldt-Jakob disease in the UK. Lancet 347, 921-925 (1996). The original case series demonstrating a new variant of CJD in the UK with atypical features, identifying the beginning of the VCJD epidemic.

26. Chazot, G. et al. New variant of Creutzfeldt-Jakob disease in a 26-year-old French man. Lancet 347, 1181 (1996).

The first identified case of vCJD in France, following the recognition of vCJD in the UK the same year.

27. Maheshwari, A. et al. Recent US case of variant Creutzfeldt-Jakob disease - global implications. Emerg. Infect. Dis. 21, 750-759 (2015).

28. European Centre for Disease Prevention and Control. Creutzfeldt-Jakob disease. Annual Epidemiological Report for 2017. (ECDC, 2020).

29. Brandel, J. P. Peckeu, L \& Haïk, S. The French surveillance network of Creutzfeldt-Jakob disease. Epidemiological data in France and worldwide. Transfus. Clin. Biol. 20, 395-397 (2013).

30. Heinemann, U. et al. Creutzfeldt-Jakob disease in Germany: a prospective 12-year surveillance. Brain 130, 1350-1359 (2007).

31. Maddox, R. A. et al. Prion disease incidence in the United States: 2003-2015. Neurology 94 e153-e157 (2020).

32. Geschwind, M. D. Prion diseases. Continuum 21, 1612-1638 (2015).

33. Ladogana, A. et al. Mortality from Creutzfeldt-Jakob disease and related disorders in Europe, Australia, and Canada. Neurology 64, 1586-1591 (2005).

34. Horan, G. et al. Creutzfeldt-Jakob disease in Ireland: epidemiological aspects 1980-2002. Eur. Neurol. 51, 132-137 (2004).

35. Velásquez-Pérez, L., Rembao-Bojorquez, D., Guevara, J. Guadarrama-Torres, R. M. \& Trejo-Contreras, A. Creutzfeldt-Jakob disease in Mexico. Neuropathology 27, 419-428 (2007)

36. Begue, C. et al. Creutzfeldt-Jakob disease surveillance in Argentina, 1997-2008. Neuroepidemiology 37, 193-202 (2011)

37. Martins, V. R., Gomes, H. R., Chimelli, L. Rosemberg, S. \& Landemberger, M. C. Prion diseases are undercompulsory notification in Brazil: surveillance of cases evaluated by biochemicaland/or genetic markers from 2005 to 2007. Dement. Neuropsychol. 1, 347-355 (2007). 
38. Adam, A. M. \& Akuku, O. Creutzfeldt-Jakob disease in Kenya. Trop. Med. Int. Health 10, 710-712 (2005).

39. Hajjaj, I. \& Kissani, N. First case of presumed sporadic Creutzfeldt-Jakob disease in Marrakech, Morocco [In French]. Med. Trop. 71, 289-291 (2011).

40. Negm, M. \& Hashish, E. Probable Creutzfeldt-Jakob disease - a case report at Suez Canal University Hospital, Egypt. Egypt. J. Neurol. Psychiatry Neurosurg. 55, 36 (2019)

41. Nozaki, I. et al. Prospective 10-year surveillance of human prion diseases in Japan. Brain 133 3043-3057 (2010)

42. Shi, Q. et al. Analysis of the advantage features of Beijing surveillance network for Creutzfeldt-Jakob disease. Prion 9, 304-314 (2015).

43. Lolekha, P., Rasheed, A. \& Yotsarawat, C. CreutzfeldtJakob disease in a tertiary care hospital in Thailand a case series and review of the literature. J. Mov. Disord. 8, 136-140 (2015).

44. Oi, C., Zhang, J. T., Zhao, W., Xing, X. W. \& Yu, S. Y. Sporadic Creutzfeldt-Jakob disease: a retrospective analysis of 104 cases. Eur Neurol. 83, 65-72 (2020).

45. Lim, J. S. et al. Characteristics of Korean patients with suspected Creutzfeldt-Jakob disease with 14-3-3 protein in cerebrospinal fluid: Preliminary study of the Korean Creutzfeldt-Jakob disease active surveillance program. Prion 9, 136-143 (2015).

46. Klug, G. M. et al. Intensity of human prion disease surveillance predicts observed disease incidence. J. Neurol. Neurosurg. Psychiatry 84, 1372-1377 (2013)

47. Stehmann, C et al. Creutzfeldt-Jakob disease surveillance in Australia: update to 31 December 2019. Commun. Dis. Intell. https://doi.org/10.33321/ cdi.2019.43.35 (2020)

48. Ahmad, A., Rao, F. \& Aieshah, S. Two cases of Creutzfeldt-Jakob disease from an ongoing dementia registry in Pakistan. J. Pak. Med. Assoc. 64, 705-707 (2014)

49. Kharel, H., Adhikari, P., Pokhrel, N. B., Kharel, Z. \& Nepal, G. The first reported case of Creutzfeldt-Jakob disease from Nepal. Clin. Case Rep. 8, 198-202 (2020).

50. Safar, J. G. Molecular pathogenesis of sporadic prion diseases in man. Prion 6, 108-115 (2012).

51. Collins, S. et al. Surgical treatment and risk of sporadic Creutzfeldt-Jakob disease: a case-control study. Lancet 353, 693-697 (1999).

52. Mahillo-Fernandez, I. et al. Surgery and risk of sporadic Creutzfeldt-Jakob disease in Denmark and Sweden: registry-based case-control studies. Neuroepidemiology 31, 229-240 (2008).

53. Puopolo, M., Ladogana, A., Vetrugno, V. \& Pocchiari, M Transmission of sporadic Creutzfeldt-Jakob disease by blood transfusion: risk factor or possible biases. Transfusion 51, 1556-1566 (2011).

54. de Pedro Cuesta, J et al Sensitivity to biases of case-control studies on medical procedures, particularly surgery and blood transfusion, and risk of CreutzfeldtJakob disease. Neuroepidemiology 39, 1-18 (2012). A review article evaluating 18 case-control studies in SCJD demonstrating the methodological challenges involved in working with CJD

55. Alperovitch, A. et al. Codon 129 prion protein genotype and sporadic Creutzfeldt-Jakob disease Lancet 353, 1673-1674 (1999).

56. Cooper, S. A., Murray, K. L., Heath, C. A., Will, R. G \& Knight, R. S. Isolated visual symptoms at onset in sporadic Creutzfeldt-Jakob disease: the clinical phenotype of the "Heidenhain variant". $B r$. J. Ophthalmol. 89, 1341-1342 (2005).

57. Hermann, P. et al. Validation and utilization of amended diagnostic criteria in Creutzfeldt-Jakob disease surveillance. Neurology 91, e331-e338 (2018)

Prospective study validating the 2017 diagnostic criteria for SCJD demonstrating a sensitivity of $97 \%$ and a specificity of $99 \%$

58. Zerr, I. et al. Updated clinical diagnostic criteria for sporadic Creutzfeldt-Jakob disease. Brain 132 2659-2668 (2009)

International study demonstrating the utility of MRI for the diagnosis of $\mathrm{SCJD}$.

59. Tschampa, H. J. et al. Pattern of cortical changes in sporadic Creutzfeldt-Jakob disease. Am. J. Neuroradiol. 28, 1114-1118 (2007).

60. Steinhoff, B. J. et al. Diagnostic value of periodic complexes in Creutzfeldt-Jakob disease. Ann. Neurol. 56, 702-708 (2004)

61. Schmitz, M. et al. Validation of 14-3-3 protein as a marker in sporadic Creutzfeldt-Jakob disease diagnostic. Mol. Neurobiol. 53, 2189-2199 (2016).
62. Chohan, G. et al. The role of cerebrospinal fluid 14-3-3 and other proteins in the diagnosis of sporadic Creutzfeldt-Jakob disease in the UK: a 10-year review. J. Neurol. Neurosurg. Psychiatry 81, 1243-1248 (2010).

63. Sanchez-Juan, P. et al. CSF tests in the differential diagnosis of Creutzfeldt-Jakob disease. Neurology 67 637-643 (2006)

64. Green, A. J. E. RT-QulC: a new test for sporadic CJD Pract. Neurol. 19, 49-55 (2019).

65. Cramm, M. et al. Stability and reproducibility underscore utility of RT-QuIC for diagnosis of Creutzfeldt-Jakob disease. Mol. Neurobiol. 53 1896-1904 (2016). International study demonstrating consistently high sensitivity of RT-QuIC and specificity of $99 \%$ for the diagnosis of CJD.

66. Atarashi, R., Sano, K., Satoh, K. \& Nishida, N. Realtime quaking-induced conversion: a highly sensitive assay for prion detection. Prion 5, 150-153 (2011)

67. Ironside, J. W., Ritchie, D. L. \& Head, M. W. Phenotypic variability in human prion diseases. Neuropathol. Appl. Neurobiol. 31, 565-579 (2005).

68. Wadsworth, J. D. \& Collinge, J. Molecular pathology of human prion disease. Acta Neuropathol. 121, 69-77 (2011).

69. Mead, S., Lloyd, S. \& Collinge, J. Genetic factors in mammalian prion diseases. Annu. Rev. Genet. 53, 117-147 (2019)

70. Mead, S. Prion disease genetics. Eur. J. Hum. Genet 14, 273-281 (2006)

71. Public Health England. Public health action following a report of a new case of CJD or a person at increased risk of CJD. https://assets. publishing.service.gov.uk/ government/uploads/system/uploads/attachment data/file/474338/CJD public health_action new case 301015.pdf (2015)

72. US Department of Health and Human Services, Food and Drug Administration. Recommendations to reduce the possible risk of transmission of Creutzfeldt-Jakob disease and variant Creutzfeldt-Jakob disease by blood and blood components. https://www.fda.gov/ media/124156/download (2020)

73. Mastrianni, J. A. The genetics of prion diseases. Genet. Med. 12, 187-195 (2010).

74. Bagyinszky, E. et al. Early-onset Alzheimer's disease patient with prion (PRNP) p.Val180lle mutation. Neuropsychiatr. Dis. Treat. 15, 2003-2013 (2019).

75. Moore, R. C. et al. Huntington disease phenocopy is a familial prion disease. Am. J. Hum. Genet. 69 1385-1388 (2001).

76. Webb, T. E. et al. Phenotypic heterogeneity and genetic modification of $\mathrm{P} 102 \mathrm{~L}$ inherited prion disease in an international series. Brain 131, 2632-2646 (2008).

77. Paucar, M. et al. Genotype-phenotype analysis in inherited prion disease with eight octapeptide repeat insertional mutation. Prion 7, 501-510 (2013).

78. Oldoni, E. et al. PRNP P39L variant is a rare cause of frontotemporal dementia in Italian population. J. Alzheimers Dis. 50, 353-357 (2016).

79. Nitrini, R. et al. Prion disease resembling frontotemporal dementia and parkinsonism linked to chromosome 17. Arq. Neuropsiquiatr. 59, 161-164 (2001).

80. Cracco, L., Appleby, B. S. \& Gambetti, P. Fatal familial insomnia and sporadic fatal insomnia. Handb. Clin. Neurol. 153, 271-299 (2018)

81. Goldfarb, L. G. et al. Fatal familial insomnia and familial Creutzfeldt-Jakob disease: disease phenotype determined by a DNA polymorphism. Science 258 806-808 (1992).

82. Takada, L. T. et al. Genetic prion disease: experience of a rapidly progressive dementia center in the United States and a review of the literature. Am. J. Med. Genet. B Neuropsychiatr. Genet. 174, 36-69 (2017).

83. Shi, Q. et al. The features of genetic prion diseases based on Chinese surveillance program. PLoS One 10 e0139552 (2015).

84. Hsiao, K. et al. Mutation of the prion protein in Libyan Jews with Creutzfeldt-Jakob disease. N. Engl. J. Med. 324, 1091-1097 (1991)

85. Ladogana, A. et al. High incidence of genetic human transmissible spongiform encephalopathies in Italy. Neurology 64, 1592-1597 (2005)

86. Montagna, P., Gambetti, P., Cortelli, P. \& Lugaresi, E. Familial and sporadic fatal insomnia. Lancet Neurol. 2 , 167-176 (2003)

87. Jeong, B. H. \& Kim, Y. S. Genetic studies in human prion diseases. J. Korean Med. Sci. 29, 623-632 (2014).
88. Melis, M. et al. Genetic Creutzfeldt-Jakob disease in Sardinia: a case series linked to the PRNP R208H mutation due to a single founder effect. Neurogenetics 21, 251-257 (2020)

89. Beck, J., Collinge, J. \& Mead, S. Prion protein gene $\mathrm{M} 232 \mathrm{R}$ variation is probably an uncommon polymorphism rather than a pathogenic mutation. Brain 135, e209 (2012).

90. Rodriguez, M. M. et al. A novel mutation (G114V) in the prion protein gene in a family with inherited prion disease. Neurology 64, 1455-1457 (2005).

91. Katrak, S. M. et al. Familial Creutzfeldt-Jakob disease in an Indian kindred. Ann. Indian. Acad. Neurol. 22, 458-461 (2019)

92. Will, R. G. Acquired prion disease: iatrogenic CJD variant CJD, kuru. Br. Med. Bull. 66, 255-265 (2003).

93. Collinge, J. et al. A clinical study of kuru patients with long incubation periods at the end of the epidemic in Papua New Guinea. Philos. Trans. R. Soc. Lond. B Biol. Sci. 363, 3725-3739 (2008)

94. Alpers, M. P. Review. The epidemiology of kuru: monitoring the epidemic from its peak to its end. Philos. Trans. R. Soc. Lond. B Biol. Sci. 363 , 3707-3713 (2008).

95. Duffy, P. et al. Letter: Possible person-to-person transmission of Creutzfeldt-Jakob disease. N. Engl. J. Med. 290, 692-693 (1974).

96. Koch, T. K., Berg, B. O., De Armond, S. J. \& Gravina, R. F. Creutzfeldt-Jakob disease in a young adult with idiopathic hypopituitarism. Possible relation to the administration of cadaveric human growth hormone. N. Engl. J. Med. 313, 731-733 (1985).

97. Boyd, A. et al. Transmissible spongiform encephalopathies in Australia. Commun. Dis. Intell. $Q$. Rep. 25, 248-252 (2001).

98. Croes, E. A., Roks, G., Jansen, G. H., Nijssen, P. C $\&$ van Duijn, C. M. Creutzfeldt-Jakob disease 38 years after diagnostic use of human growth hormone. J. Neurol. Neurosurg. Psychiatry 72, 792-793 (2002).

99. Brown, P., Brandel, J.-P., Preese, M. \& Sato, T latrogenic Creutzfeldt-Jakob disease: the waning of an era. Neurology 67, 389-393 (2006).

100. Ae, R. et al. Update: dura mater graft-associated Creutzfeldt-Jakob disease - Japan, 1975-2017. MMWR Morb. Mortal Wkly Rep. 67, 274-278 (2018).

Most recently published report on dura mater graft-associated iCJD in Japan, the centre of the global epidemic.

101. US Department of Health and Human Services, Food and Drug Administration. Guidance for Industry and FDA Staff. Class II Special Controls Guidance Document: Human Dura Mater https://www.fda.gov/ media/71309/download (2003).

102. World Health Organization. WHO Infection Control Guidelines for Transmissible Spongiform Encephalopathies. Report of a WHO consultation Geneva, Switzerland, 23-26 March 1999. (WHO, 1999).

103. Cali, I. et al. Distinct pathological phenotypes of Creutzfeldt-Jakob disease in recipients of prioncontaminated growth hormone. Acta Neuropathol. Commun. 3, 37 (2015)

104. Hamaguchi, T. et al. Insight into the frequent occurrence of dura mater graft-associated CreutzfeldtJakob disease in Japan. J. Neurol. Neurosurg. Psychiatry 84, 1171-1175 (2013).

105. Abrams, J. Y. et al. Lower risk of Creutzfeldt-Jakob disease in pituitary growth hormone recipients initiating treatment after 1977. J. Clin. Endocrinol. Metab. 96, E1666-E1669 (2011).

106. Brandel, J. P. et al. Distribution of codon 129 genotype in human growth hormone-treated CJD patients in France and the UK. Lancet 362, 128-130 (2003).

107. Zeidler, M. et al. New variant Creutzfeldt-Jakob disease: neurological features and diagnostic tests. Lancet 350, 903-907 (1997)

108. National CJD Research \& Surveillance Unit. Creutzfeldt-Jakob Disease Surveillance in the UK. 27th Annual Report 2018. http://www.cjd.ed.ac.uk/sites/ default/files/report27.pdf (2019).

109. Spencer, M. D., Knight, R. S. \& Will, R. G. First hundred cases of variant Creutzfeldt-Jakob disease: retrospective case note review of early psychiatric and neurological features. BMJ 324, 1479-1482 (2002). Cohort study of 100 individuals with vCJD describing the clinical features important for diagnosis and surveillance. 
110. Heath, C. A. et al. Validation of diagnostic criteria for variant Creutzfeldt-Jakob disease. Ann. Neurol 67 761-770 (2010)

111. Collie, D. A. et al. Diagnosing variant CreutzfeldtJakob disease with the pulvinar sign: MR imaging findings in 86 neuropathologically confirmed cases. Am. J. Neuroradiol. 24, 1560-1569 (2003). Large study characterizing the pulvinar thalamic abnormalities seen on MRI in vCJD.

112. Green, A. J. E. et al. Use of $14-3-3$ and other brain specific proteins in CSF in the diagnosis of variant Creutzfeldt-Jakob disease. J. Neurol. Neurosurg. Psychiatry 70, 744 (2001)

113. Ironside, J. W. Neuropathology of variant CreutzfeldtJakob disease. C. R. Biol. 325, 27-31 (2002)

114. Ward, H. J. et al. Risk factors for variant CreutzfeldtJakob disease: a case-control study. Ann. Neurol. 59 111-120 (2006).

115. Ironside, J. W. Variant Creutzfeldt-Jakob disease. Haemophilia 16, 175-180 (2010).

116. Brown, P. Bovine spongiform encephalopathy and variant Creutzfeldt-Jakob disease. BMJ 322 , 841-844 (2001)

117. Food Standards Agency. Bovine Spongiform Encephalopathy. Food Standards Agency https:// www.food.gov.uk/safety-hygiene/bovinespongiform-encephalopathy-bse (2017)

118. World Organization for Animal Health. Bovine Spongiform Encephalopathy (BSE) https://www.oie.int/ en/animal-health-in-the-world/animal-diseases/Bovinespongiform-encephalopathy/ (2018).

119. Centers for Disease Control and Prevention. Bovine Spongiform Encephalopathy (BSE), or Mad Cow Disease. Control Measures https://www.cdc.gov/ prions/bse/control-measures.html (2018).

120. The European Parliament. Regulation $(E C)$ no 999/2001 of the European Parliament and of the Council as of 22 May 2001 laying down rules for the prevention, control and eradication of certain transmissible spongiform encephalopathies. Official Journal of the European Communities L147/1-40. https://eur-lex.europa.eu/legal-content/EN/TXT/ HTML/?uri=CELEX:32001R0999\&from=EN (2001)

121. BBC News. Timeline: British Beef Ban http://news.bbc co.uk/2/hi/uk_news/4785610.stm\#: : text= MARCH $\% 201996$,live $\% 20$ cattle $\% 2$ C $\%$ meat $\% 20$ and $\% 20$ products (2006)

122. Bradley, R. \& Wilesmith, J. W. Epidemiology and control of bovine spongiform encephalopathy (BSE). Br. Med. Bull. 49, 932-959 (1993)

123. Collinge, J., Sidle, K. C., Meads, J., Ironside, J. $\&$ Hill, A. F. Molecular analysis of prion strain variation and the aetiology of 'new variant' CJD. Nature 383 685-690 (1996).

Landmark study demonstrating molecular characteristics and transmission properties of vCJD-associated prion protein with similarity to that seen in BSE, suggesting BSE was the source of vCJD

124. Palmer Clephan, M. A week that shook the meat industry: the effects on the UK beef industry of the BSE crisis. Br. Food J. 98, 17-25 (1996).

125. Food Standards Agency. BSE and Beef. New Controls Explained. Advicsory Committee for Social Science https://acss.food.gov.uk/sites/default/files/multimedia/ pdfs/publication/bsebooklet.pdf (2006).

126. BBC News. UK Beef Export Ban Lifted by EU http:// news.bbc.co.uk/1/hi/uk/4784810.stm (2006).

127. European Commission. BSE: UK Embargo to be Lifted https://ec.europa.eu/commission/presscorner/detail/ en/IP_06_278 (2006)

128. BBC News. UK Beef Exports to US Resume after more than 20 years https://www.bbc.co.uk/news/ business-54347426 (2020)

129. Fickling, D. EU Lifts Ban on British Beef Exports https://www.theguardian.com/uk/2006/may/03/bse.eu (2006).

130. BBC News. 'Mad cow disease': What is BSE? https://www.bbc.co.uk/news/uk-45906585 (2018).

131. Cooper, J. D. \& Bird, S. M. UK bovine carcass meat consumed as burgers, sausages and other meat products: by birth cohort and gender. J. Cancer Epidemiol. Prev. 7, 49-57 (2002)

132. Cooper, J. D. \& Bird, S. M. UK dietary exposure to BSE in beef mechanically recovered meat: by birth cohort and gender. J. Cancer Epidemiol. Prev. 7 59-70 (2002).

133. Cooper, J. D. \& Bird, S. M. UK dietary exposure to BSE in head meat: by birth cohort and gender. J. Cancer Epidemiol. Prev. 7, 71-83 (2002).

134. Chen, C.-C. \& Wang, Y.-H. Estimation of the exposure of the UK population to the bovine spongiform encephalopathy agent through dietary intake during the period 1980 to 1996. PLoS One 9 , e94020 (2014).

135. Chadeau-Hyam, M. et al. Estimation of the exposure of the French population to the BSE agent: comparison of the 1980-95 consumption of beef products containing mechanically recovered meat in France and the UK, by birth cohort and gender. Stat. Methods Med. Res. 12, 247-260 (2003).

136. Reuters. France confirms case of mad cow disease Reuters https://www.reuters.com/article/us france-madcow-idUSKCNOWO15S (2016).

137. BBC News. 'Mad cow disease' at Aberdeenshire farm after BSE confirmed https://www.bbc.co.uk/news/uk scotland-north-east-orkney-shetland-45901043 (2018)

138. Bruce, M. E. et al. Transmissions to mice indicate that 'new variant' CJD is caused by the BSE agent. Nature 389, 498-501 (1997).

139. Lasmezas, C. I. et al. BSE transmission to macaques. Nature 381, 743-744 (1996).

140. Collinge, J. et al. Unaltered susceptibility to BSE in transgenic mice expressing human prion protein. Nature 378, 779-783 (1995).

141. Will, R. G., Matthews, W. B., Smith, P. G. \& Hudson, C. A retrospective study of Creutzfeldt-Jakob disease in England and Wales 1970-1979. II: Epidemiology. J. Neurol. Neurosurg. Psychiatry 49 749-755 (1986)

142. Will, R. G. et al. Descriptive epidemiology of Creutzfeldt-Jakob disease in six European countries, 1993-1995. Ann. Neurol. 43, 763-767 (1998).

143. Puopolo, M. et al. Mortality trend from sporadic Creutzfeldt-Jakob disease (CJD) in Italy, 1993-2000. J. Clin. Epidemiol. 56, 494-499 (2003).

144. Nakamura, Y. et al. Incidence rate of Creutzfeldt-Jakob disease in Japan. Int. J. Epidemiol. 28, 130-134 (1999).

145. Case Western Reserve University. National Prion Disease Pathology Surveillance Center https://case. edu/medicine/pathology/divisions/prion-center (2021).

146. Brandel, J. P. et al. Variant Creutzfeldt-Jakob disease in France and the United Kingdom: evidence for the same agent strain. Ann. Neurol. 65, 249-256 (2009).

147. Riverol, M. et al. Variant Creutzfeldt-Jakob disease occurring in mother and son. J. Neurol. Neurosurg. Psychiatry 83, 235-236 (2012).

148. Coulthart, M. B. et al. A case cluster of variant Creutzfeldt-Jakob disease linked to the Kingdom of Saudi Arabia. Brain 139, 2609-2616 (2016).

149. Kaski, D. et al. Variant CJD in an individual heterozygous for PRNP codon 129. Lancet 374, 2128 (2009).

150. Wells, G. A. et al. A novel progressive spongiform encephalopathy in cattle. Vet. Rec. 121, 419-420 (1987).

151. Appleby, B. S. et al. Characteristics of established and proposed sporadic Creutzfeldt-Jakob disease variants. Arch. Neurol. 66, 208-215 (2009).

152. Hamaguchi, T. et al. Clinical diagnosis of MM2-type sporadic Creutzfeldt-Jakob disease. Neurology 64 , 643-648 (2005)

153. Krasnianski, A. et al. Clinical findings and diagnostic tests in the MV2 subtype of sporadic CJD. Brain 129 2288-2296 (2006).

154. Meissner, B. et al. Sporadic Creutzfeldt-Jakob disease clinical and diagnostic characteristics of the rare VV1 type. Neurology 65, 1544-1550 (2005).

155. National CJD Research and Surveillance Unit. Estimation of the incidence of variant Creutzfeldt Jakob disease diagnoses and deaths in the UK January 1994-December 2011 https://www.cjd.ed. ac.uk/sites/default/files/cjdq72.pdf (2012).

156. Klitzman, R. L. Incubation period of human prion disease. Lancet 368, 913 (2006).

157. Moore, R. A., Vorberg, I. \& Priola, S. A. Species barriers in prion diseases-brief review. Arch. Virol. Suppl. 19, 187-202 (2005).

158. Hagiwara, K. I. Hara, H. \& Hanada, K. Species-barrier phenomenon in prion transmissibility from a viewpoint of protein science. J. Biochem. 153, 139-145 (2013)

159. Hewitt, P. E., Llewelyn, C. A., Mackenzie, J. \& Will, R. G. Creutzfeldt-Jakob disease and blood transfusion: results of the UK transfusion medicine epidemiological review study. Vox Sang. 91, 221-230 (2006). UK surveillance study demonstrating two case of transfusion-transmitted vCJD and another case of pre-clinical vCJD

160. Urwin, P. J., Mackenzie, J. M., Llewelyn, C. A., Will, R. C. $\&$ Hewitt, P. E. Creutzfeldt-Jakob disease and blood transfusion: updated results of the UK Transfusion Medicine Epidemiology Review Study. Vox Sang. 110, 310-316 (2016)
161. Wadsworth, J. D. et al. Tissue distribution of protease resistant prion protein in variant Creutzfeldt-Jakob disease using a highly sensitive immunoblotting assay. Lancet 358, 171-180 (2001)

Autopsy study demonstrating peripheral presence of prion protein in the lymphoreticular system of individuals with vCJD.

162. Hilton, D. A. et al. Specificity of lymphoreticular accumulation of prion protein for variant CreutzfeldtJakob disease. J. Clin. Pathol. 57, 300-302 (2004).

163. Notari, S. et al. Multiorgan detection and characterization of protease-resistant prion protein in a case of variant CJD examined in the United States. PLoS One 5, e8765 (2010).

164. Hilton, D. A. Pathogenesis and prevalence of variant Creutzfeldt-Jakob disease. J. Pathol. 208, 134-141 (2006).

165. Hilton, D. A. et al. Prevalence of lymphoreticular prion protein accumulation in UK tissue samples. J. Pathol. 203, 733-739 (2004)

The first in a trilogy of studies demonstrating prevalent abnormal prion protein in resected appendix tissues derived from UK individuals exposed to BSE.

166. Gill, O. N. et al. Prevalent abnormal prion protein in human appendixes after bovine spongiform encephalopathy epizootic: large scale survey. BMJ 347, f5675 (2013).

The second in a trilogy of studies demonstrating prevalent abnormal prion protein in resected appendix tissues derived from UK individuals exposed to BSE

167. Gill, O. N. et al. Prevalence in Britain of abnorma prion protein in human appendices before and after exposure to the cattle BSE epizootic. Acta Neuropathol 139, 965-976 (2020). The third in a trilogy of studies, demonstrating abnormal prion protein in appendices resected from UK individuals outside of the established window of exposure to BSE.

168. Clewley, J. P. et al. Prevalence of disease related prion protein in anonymous tonsil specimens in Britain: cross sectional opportunistic survey. BMJ 338, b1442 (2009).

169. Hill, A. F. et al. Investigation of variant CreutzfeldtJakob disease and other human prion diseases with tonsil biopsy samples. Lancet 353, 183-189 (1999).

170. Wroe, S. J. et al. Clinical presentation and pre-mortem diagnosis of variant Creutzfeldt-Jakob disease associated with blood transfusion: a case report. Lancet 368, 2061-2067 (2006)

171. Llewelyn, C. A. et al. Possible transmission of variant Creutzfeldt-Jakob disease by blood transfusion. Lancet 363, 417-421 (2004).

172. Peden, A. H., Head, M. W., Ritchie, D. L., Bell, J. E. \& Ironside, J. W. Preclinical vCJD after blood transfusion in a PRNP codon 129 heterozygous patient. Lancet 364, 527-529 (2004).

173. Davidson, L. R., Llewelyn, C. A., Mackenzie, J. M. Hewitt, P. E. \& Will, R. G. Variant CJD and blood transfusion: are there additional cases? Vox Sang. 107, 220-225 (2014).

174. Peden, A. et al. Variant CJD infection in the spleen of a neurologically asymptomatic UK adult patient with haemophilia. Haemophilia 16, 296-304 (2010).

175. Houston, F., Foster, J. D., Chong, A., Hunter, N. $\&$ Bostock, C. J. Transmission of BSE by blood transfusion in sheep Lancet 356, 999-1000 (2000)

176. McCutcheon, S. et al. All clinically-relevant blood components transmit prion disease following a single blood transfusion: a sheep model of vCJD. PLoS One 6, e23169 (2011).

177. Bishop, M. T. et al. Prion infectivity in the spleen of a PRNP heterozygous individual with subclinical variant Creutzfeldt-Jakob disease. Brain 136, 1139-1145 (2013).

178. Clarke, P., Will, R. G. \& Ghani, A. C. Is there the potential for an epidemic of variant Creutzfeldt-Jakob disease via blood transfusion in the UK? J. R. Soc Interface 4, 675-684 (2007).

179. Garske, T. $\&$ Ghani, A. C. Uncertainty in the tail of the variant Creutzfeldt-Jakob disease epidemic in the UK. PLoS One 5, e15626 (2010).

180. Department of Health \& Social Care. Risk assessment of the transmission of $v C J D$ by blood components https://assets.publishing.service.gov.uk/government/ uploads/system/uploads/attachment_data/ file/843533/risk-assessment-of-the-transmissionof-vcjd-by-blood-components. pdf (2019).

181. Bennett, P. \& Daraktchiev, M. vCJD and transfusion of blood components: an updated risk assessment. (Department of Health, 2013). 
182. Crowder, L. A., Schonberger, L. B., Dodd, R. Y. \& Steele, W. R. Creutzfeldt-Jakob disease lookback study: 21 years of surveillance for transfusion transmission risk. Transfusion 57, 1875-1878 (2017).

183. Holmqvist, J. et al. No evidence of transfusion transmitted sporadic Creutzfeldt-Jakob disease: results from a bi-national cohort study. Transfusion 60, 694-697 (2020).

184. Riggs, J. E., Moudgil, S. S. \& Hobbs, G. R. CreutzfeldtJakob disease and blood transfusions: a meta-analysis of case-control studies. Mil. Med. 166, 1057-1058 (2001).

185. Wilson, K., Code, C. \& Ricketts, M. N. Risk of acquiring Creutzfeldt-Jakob disease from blood transfusions: systematic review of case-control studies. BMJ 321 , 17-19 (2000).

186. Urwin, P. et al. Sporadic Creutzfeldt-Jakob disease in 2 plasma product recipients, United Kingdom. Emerg. Infect. Dis. 23, 893-897 (2017)

187. UK Government. Advisory committee on the safety of blood, tissues and organs. paediatric components working group - report. importation of plasma and use of apheresis platelets as risk reduction measures for variant Creutzfeldt-Jakob Disease https://assets. publishing.service.gov.uk/government/uploads/ system/uploads/attachment data/file/829906/ SaBTO_PC_report.pdf (2019).

188. Concha-Marambio, L. et al. Detection of prions in blood from patients with variant Creutzfeldt-Jakob disease. Sci. Transl. Med. 8, 370ra183 (2016).

189. Bougard, D. et al. Detection of prions in the plasma of presymptomatic and symptomatic patients with variant Creutzfeldt-Jakob disease. Sci. Transl. Med. 8, 370ra182 (2016)

190. Castilla, J., Saá, P., Hetz, C. \& Soto, C. In vitro generation of infectious scrapie prions. Cell 121 , 195-206 (2005)

191. Moudjou, M. et al. Highly infectious prions generated by a single round of microplate-based protein misfolding cyclic amplification. mBio 5, e00829-13 (2013).

192. Cali, I. et al. PMCA-replicated PrP(D) in urine of vCJD patients maintains infectivity and strain characteristics of brain PrP(D): transmission study. Sci. Rep. 9, 5191 (2019).

193. Department of Health \& Social Care. Transmissible spongiform encephalopathy agents: safe working and the prevention of infection. part 3: laboratory containment and control measures https://assets. publishing.service.gov.uk/government/uploads/ system/uploads/attachment_data/file/209757/ Part_3_-_Laboratory_containment and control measures.pdf (2003).

194. Honda, H. et al. Abnormal prion protein deposits with high seeding activities in the skeletal muscle, femoral nerve, and scalp of an autopsied case of sporadic Creutzfeldt-Jakob disease. Neuropathology https:// doi.org/10.1111/neup.12717 (2021).

195. Glatzel, M., Abela, E., Maissen, M. \& Aguzzi, A. Extraneural pathologic prion protein in sporadic Creutzfeldt-Jakob disease. N. Engl. J. Med. 349, 1812-1820 (2003)

196. Takao, M., Kimura, H., Kitamoto, T. \& Mihara, B. PrPres deposition in the retina is a common finding of sporadic, familial and iatrogenic Creutzfeldt-Jakob diseases (CJD). Acta Neuropathol. Commun. 6, 78 (2018).

197. Head, M. W. et al. Prion protein accumulation in eyes of patients with sporadic and variant CreutzfeldtJakob disease. Invest. Ophthalmol. Vis. Sci. 44 342-346 (2003)

198. Kresl, P. et al. Accumulation of prion protein in the vagus nerve in Creutzfeldt-Jakob disease. Ann. Neurol. 85, 782-787 (2019).

199. Orru, C. D. et al. Prion seeding activity and infectivity in skin samples from patients with sporadic Creutzfeldt-Jakob disease. Sci. Transl. Med. 9 , eaam7785 (2017).

200. Mammana, A. et al. Detection of prions in skin punch biopsies of Creutzfeldt-Jakob disease patients. Ann. Clin. Transl. Neurol. 7, 559-564 (2020).

201. Huor, A. et al. Infectivity in bone marrow from sporadic CJD patients. J. Pathol. 243, 273-278 (2017).

202. Ruegger, J. et al. A case-control study of sporadic Creutzfeldt-Jakob disease in Switzerland: analysis of potential risk factors with regard to an increased CJD incidence in the years 2001-2004. BMC Public Health 9, 18 (2009)

203. Belondrade, M. et al. Correlation between bioassay and protein misfolding cyclic amplification for variant
Creutzfeldt-Jakob disease decontamination studies. mSphere 5, e00649-19 (2020).

204. Notari, S. et al. Assessing prion infectivity of human urine in sporadic Creutzfeldt-Jakob disease. Emerg. Infect. Dis. 18, 21-28 (2012).

205. Moda, F. et al. Prions in the urine of patients with variant Creutzfeldt-Jakob disease. N. Engl. J. Med. 371, 530-539 (2014).

206. Van Dorsselaer, A. et al. Detection of prion protein in urine-derived injectable fertility products by a targeted proteomic approach. PLoS One 6, e17815 (2011).

207. Wientjens, D. P. et al. Risk factors for CreutzfeldtJakob disease: a reanalysis of case-control studies. Neurology 46, 1287-1291 (1996)

208. Cocco, P. L., Caperna, A. \& Vinci, F. Occupational risk factors for the sporadic form of Creutzfeldt-Jakob disease. Med. Lav. 94, 353-363 (2003).

209. Alcalde-Cabero, E. et al. Health professions and risk of sporadic Creutzfeldt-Jakob disease, 1965 to 2010. Euro Surveill. 17, 20144 (2012).

210. Hermann, P. et al. Sporadic Creutzfeldt-Jakob disease among physicians, Germany, 1993-2018. Emerg. Infect. Dis. 26, 1710-1719 (2020).

211. Tenny, S., Kerndt, C. C. \& Hoffman, M. R. in StatPearls (StatPearls Publishing LLC., 2021).

212. Government of Canada. Creutzfeldt-Jakob Disease Surveillance System (CJDSS) Report https://www. canada.ca/en/public-health/services/surveillance/ blood-safety-contribution-program/creutzfeldt-jakobdisease/cjd-surveillance-system.html (2021).

213. Centers for Disease Control and Prevention. Creutzfeldt-Jakob Disease, Classic (CJD). Occurrence and Transmission https://www.cdc.gov/prions/cjd/ occurrence-transmission.html (2019).

214. Nishimura, Y. et al. A nationwide trend analysis in the incidence and mortality of Creutzfeldt-Jakob disease in Japan between 2005 and 2014. Sci. Rep. 10, 15509 (2020)

215. Rhoads, D. D. et al. Diagnosis of prion diseases by RT-QuIC results in improved surveillance. Neurology 95, e1017-e1026 (2020)

216. Murray, K et al. Is there evidence of vertical transmission of variant Creutzfeldt-Jakob disease? J. Neurol. Neurosurg. Psychiatry 82, 729-731 (2011).

217. Puopolo, M. et al. Spatial epidemiology of sporadic Creutzfeldt-Jakob disease in Apulia, Italy. Neuroepidemiology 54, 83-90 (2020).

218. Klug, G. M. et al. Enhanced geographically restricted surveillance simulates sporadic Creutzfeldt-Jakob disease cluster. Brain 132, 493-501 (2009).

219. Hannaoui, S., Schatzl, H. M. \& Gilch, S. Chronic wasting disease: Emerging prions and their potential risk. PLoS Pathog. 13, e 1006619 (2017). Review article summarizing the chronic wasting disease epizootic in deer and elk.

220. Osterholm, M. T. et al. Chronic wasting disease in cervids: implications for prion transmission to humans and other animal species. mBio 10, e01091-19 (2019).

221. Våge, J. Chronic Wasting Disease (CWD) identified in a wild reindeer at Hardanger Plateau https:// www vetinst.no/en/news/chronic-wasting-diseasecwd-identified-in-a-wild-reindeer-at-hardanger-plateau (Norwegian Veterinary Institute, 2020).

222. Mathiason, C. K. et al. Infectious prions in the saliva and blood of deer with chronic wasting disease. Science 314, 133-136 (2006).

223. Haley, N. J. et al. Detection of chronic wasting disease prions in salivary, urinary, and intestinal tissues of deer: potential mechanisms of prion shedding and transmission. J. Virol. 85, 6309-6318 (2011).

224. Tamguney, G. et al. Asymptomatic deer excrete infectious prions in faeces. Nature 461, 529-532 (2009).

225. Tennant, J. M. et al. Shedding and stability of CWD prion seeding activity in cervid feces. PLoS One 15 e0227094 (2020)

226. Miller, M. W., Williams, E. S., Hobbs, N. T. \& Wolfe, L. L. Environmental sources of prion transmission in mule deer. Emerg. Infect. Dis. 10, 1003-1006 (2004).

227. Mathiason, C. K. et al. Infectious prions in pre-clinical deer and transmission of chronic wasting disease solely by environmental exposure. PLoS One 4, e5916 (2009).

228. Yuan, Q., Telling, G., Bartelt-Hunt, S. L. \& Bartz, J. C. Dehydration of prions on environmentally relevant surfaces protects them from inactivation by freezing and thawing. J. Virol. 92, e02191-17 (2018).

229. Angers, R. C. et al. Prions in skeletal muscles of deer with chronic wasting disease. Science 311, 1117 (2006).
230. Raymond, G. J. et al. Transmission and adaptation of chronic wasting disease to hamsters and transgenic mice: evidence for strains. J. Virol. 81, 4305-4314 (2007).

231. Di Bari, M. A. et al. Chronic wasting disease in bank voles: characterisation of the shortest incubation time model for prion diseases. PLoS Pathog. 9, e1003219 (2013).

232. Perrott, M. R., Sigurdson, C. J., Mason, G. L. \& Hoover, E. A. Mucosal transmission and pathogenesis of chronic wasting disease in ferrets. J. Gen. Virol. 94, 432-442 (2013).

233. Mathiason, C. K. et al. Susceptibility of domestic cats to chronic wasting disease. J. Virol. 87, 1947-1956 (2013).

234. Hamir, A. N. et al. Transmission of chronic wasting disease of mule deer to Suffolk sheep following intracerebral inoculation. J. Vet. Diagn. Invest. 18, 558-565 (2006).

235. Hamir, A. N. et al. Experimental transmission of chronic wasting disease agent from mule deer to cattle by the intracerebral route. J. Vet. Diagn. Invest. 17 276-281 (2005).

236. Marsh, R. F., Kincaid, A. E., Bessen, R. A. \& Bartz, J. C. Interspecies transmission of chronic wasting disease prions to squirrel monkeys (Saimiri sciureus). J. Virol. 79, 13794-13796 (2005).

237. Race, B. et al. Lack of transmission of chronic wasting disease to cynomolgus macaques. J. Virol. 92, e00550-18 (2018).

238. Kong, Q. et al. Chronic wasting disease of elk: transmissibility to humans examined by transgenic mouse models. J. Neurosci. 25, 7944-7949 (2005).

239. Barria, M. A. et al. Molecular barriers to zoonotic transmission of prions. Emerg. Infect. Dis. 20, 88-97 (2014).

240. Kurt, T. D. et al. Human prion protein sequence elements impede cross-species chronic wasting disease transmission. J. Clin. Invest. 125, 2548 (2015).

241. Olszowy, K. M. et al. Six-year follow-up of a pointsource exposure to CWD contaminated venison in an upstate New York community: risk behaviours and health outcomes 2005-2011. Public Health 128, 860-868 (2014).

242. Abrams, J. Y., Maddox, R. A., Harvey, A. R., Schonberger, L. B. \& Belay, E. D. Travel history, hunting, and venison consumption related to prion disease exposure, 2006-2007 FoodNet Population Survey. J. Am. Diet. Assoc. 111, 858-863 (2011).

243. Williams, E. S. Chronic wasting disease. Vet. Pathol. 42, 530-549 (2005)

244. Miller, M. W. et al. Epizootiology of chronic wasting disease in free-ranging cervids in Colorado and Wyoming. J. WildI. Dis. 36, 676-690 (2000).

245. Edmunds, D. R. et al. Chronic wasting disease drives population decline of white-tailed deer. PLoS One 11, e0161127 (2016).

246. Zobeley, E., Flechsig, E., Cozzio, A., Enari, M. \& Weissmann, C. Infectivity of scrapie prions bound to a stainless steel surface. Mol. Med. 5, 240-243 (1999).

247. Flechsig, E. et al. Transmission of scrapie by steel-surface-bound prions. Mol. Med. 7, 679-684 (2001).

248. Luhr, K. M., Löw, P., Taraboulos, A., Bergman, T. \& Kristensson, K. Prion adsorption to stainless steel is promoted by nickel and molybdenum. J. Gen. Virol. 90, 2821-2828 (2009).

249. Bartz, J. C., Marsh, R. F., McKenzie, D. I. \& Aiken, J. M The host range of chronic wasting disease is altered on passage in ferrets. Virology 251, 297-301 (1998).

250. Padilla, D. et al. Sheep and goat BSE propagate more efficiently than cattle BSE in human PrP transgenic mice. PLoS Pathog. 7, e1001319 (2011).

251. Espinosa, J. C. et al. Transgenic mice expressing porcine prion protein resistant to classical scrapie but susceptible to sheep bovine spongiform encephalopathy and atypical scrapie. Emerg. Infect. Dis. 15, 1214-1221 (2009)

252. Babelhadj, B. et al. Prion disease in dromedary camels, Algeria. Emerg. Infect. Dis. 24, 1029-1036 (2018).

First detection of a novel prion disease affecting camels in Algeria, not believed to be related to any known prion diseases.

253. World Organization for Animal Health. Camel prion disease: a possible emerging disease in dromedary camel populations? https://oiebulletin.com/wpcontent/uploads/2019/12/OIE-News-December2019-Camel-prion-disease.pdf (2019). 
254. Horigan, V. et al. Assessing the aggregated probability of entry of a novel prion disease agent into the United Kingdom. Microb. Risk Anal. 16, 100134 (2020).

255. Food and Agriculture Organization of the United Nations. Data: live animals http://www.fao.org/faostat en/\#data/QA (2020).

256. Northern Territory Government. Environment: animals. Feral camel https://nt.gov.au/environment animals/feral-animals/feral-camel (2015)

257. Jaunmuktane, Z. et al. Evidence for human transmission of amyloid-beta pathology and cerebral amyloid angiopathy. Nature 525, 247-250 (2015). Autopsy study of eight individuals with iCJD demonstrating that amyloid- $\beta$ may be transmissible via cadaveric hormone injection, analogous to prion protein.

258. Jaunmuktane, Z. et al. Evidence of amyloid-beta cerebral amyloid angiopathy transmission through neurosurgery. Acta Neuropathol. 135, 671-679 (2018)

259. Banerjee, G. et al. Early onset cerebral amyloid angiopathy following childhood exposure to cadaveric dura. Ann. Neurol. 85, 284-290 (2019).

260. Purro, S. A. et al. Transmission of amyloid-beta protein pathology from cadaveric pituitary growth hormone. Nature 564, 415-419 (2018).

261. Eisele, Y. S. et al. Peripherally applied Abetacontaining inoculates induce cerebral betaamyloidosis. Science 330, 980-982 (2010).

262. Olanow, C. W. \& Brundin, P. Parkinson's disease and alpha synuclein: is Parkinson's disease a prion-like disorder? Mov. Disord. 28, 31-40 (2013).

263. Ayers, J. I., Fromholt, S. E., O’Neal, V. M., Diamond, J. H. \& Borchelt, D. R. Prion-like propagation of mutant SOD1 misfolding and motor neuron disease spread along neuroanatomical pathways. Acta Neuropathol. 131, 103-114 (2016).

264. Clavaguera, F. et al. Brain homogenates from human tauopathies induce tau inclusions in mouse brain. Proc. Natl Acad. Sci. USA 110, 9535-9540 (2013).

265. Hamaguchi, T. et al. Significant association of cadaveric dura mater grafting with subpial Abeta deposition and meningeal amyloid angiopathy. Acta Neuropathol. 132, 313-315 (2016).

266. Muayqil, T., Gronseth, G. \& Camicioli, R. Evidencebased guideline: diagnostic accuracy of CSF 14-3-3 protein in sporadic Creutzfeldt-Jakob disease: report of the guideline development subcommittee of the American Academy of Neurology. Neurology 79. 1499-1506 (2012).

267. National CJD Research \& Surveillance Unit. Diagnostic criteria for Creutzfeldt-Jakob disease https://www.cjd. ed.ac.uk/sites/default/files/criteria.pdf (2017)
268. National CJD Research $\&$ Surveillance Unit. Protocol. Surveillance of CJD in the UK https.//www.cjd.ed ac uk sites/default/files/NCJDRSU\%20surveillance $\% 20$ protocol-april\%202017\%20rev2.pdf (2017).

269. European Centre for Disease Prevention and Control. EU case definition https://www.ecdc.europa.eu/en infectious-diseases-public-health/variantcreutzfeldt-jakob-disease/eu-case-definition (2017).

270. McNiven, K. et al. Enteral feeding is associated with longer survival in the advanced stages of prion disease. Brain Commun. 1, fcz012 (2019).

271. Mead, S. \& Rudge, P. CJD mimics and chameleons. Pract. Neurol. 17, 113-121 (2017).

272. Otto, M. et al. Efficacy of flupirtine on cognitive function in patients with CJD: a double-blind study. Neurology 62, 714-718 (2004)

273. Haik, S. et al. Doxycycline in Creutzfeldt-Jakob disease: a phase 2, randomised, double-blind, placebo-controlled trial. Lancet Neurol. 13, 150-158 (2014).

274. Tsuboi, Y., Doh-Ura, K. \& Yamada, T. Continuous intraventricular infusion of pentosan polysulfate: clinical trial against prion diseases. Neuropathology 29, 632-636 (2009)

275. Stewart, L. A., Rydzewska, L. H., Keogh, G. F. \& Knight, R. S. Systematic review of therapeutic interventions in human prion disease. Neurology 70 1272-1281 (2008).

276. Collinge, J. et al. Safety and efficacy of quinacrine in human prion disease (PRION-1 study): a patientpreference trial. Lancet Neurol. 8, 334-344 (2009).

277. Geschwind, M. D. et al. Quinacrine treatment trial for sporadic Creutzfeldt-Jakob disease. Neurology 81, 2015-2023 (2013).

278. Varges, D. et al. Doxycycline in early CJD: a doubleblinded randomised phase II and observational study. J. Neurol. Neurosurg. Psychiatry 88, 119-125 (2017).

279. Barbosa, B. et al. Second-Generation RT-QulC Assay for the diagnosis of Creutzfeldt-Jakob disease patients in Brazil. Front. Bioeng. Biotechnol. 8, 929 (2020).

280. Watson, N. et al. Application of telehealth for comprehensive Creutzfeldt-Jakob disease surveillance in the United Kingdom. J. Neurol. Sci. 420, 117221 (2020).

281. Appleby, B. S. et al. Feasibility of remote assessment of human prion diseases for research and surveillance. Dement. Geriatr. Cogn. Disord. 47, 79-90 (2019).

282. Klein, B. C. \& Busis, N. A. COVID-19 is catalyzing the adoption of teleneurology. Neurology 94, 903-904 (2020).

283. Abu-Rumeileh, S. et al. Comparison between plasma and cerebrospinal fluid biomarkers for the early diagnosis and association with survival in prion disease. J. Neurol. Neurosurg. Psychiatry 91, 1181-1188 (2020)

284. Cooper, S. K. et al. Detection of CWD in cervids by RT-QuIC assay of third eyelids. PLoS One 14 e0221654 (2019)

285. John, T. R., Schatzl, H. M. \& Gilch, S. Early detection of chronic wasting disease prions in urine of pre-symptomatic deer by real-time quaking-induced conversion assay. Prion 7, 253-258 (2013).

286. Renard, D., Castelnovo, G., Collombier, L., Thouvenot, E. \& Boudousq, V. FDG-PET in Creutzfeldt-Jakob disease: analysis of clinical-PET correlation. Prion 11 440-453 (2017)

287. Vallabh, S. M., Minikel, E. V., Schreiber, S. L. \& Lander, E. S. Towards a treatment for genetic prion disease: trials and biomarkers. Lancet Neurol. 19, 361-368 (2020).

288. National CJD Research and Surveillance Unit. Creutzfeldt-Jakob disease in the UK (by calendar year) https://www.cjd.ed.ac.uk/sites/default/files/ figs.pdf (2021).

\section{Acknowledgements}

This work was carried out on behalf of the European Creutzfeldt-Jakob Disease Surveillance Network, which is funded by European Centre for Disease Prevention and Control.

\section{Author contributions}

S.P. and N.W. researched data for the article, made a substantial contribution to discussion of content, wrote the article, and reviewed and edited the manuscript before submission. J.-P.B., P.H., A.L. and J.M. made a substantial contribution to discussion of content and reviewed and edited the manuscript before submission. A.G., M.P. C.S. and I.Z. reviewed and edited the manuscript before submission. T.L. researched data for the article.

\section{Competing interests}

The authors declare no competing interests.

\section{Peer review information}

Nature Reviews Neurology thanks B. Appleby, E. Belay and the other, anonymous, reviewer(s) for their contribution to the peer review of this work.

\section{Publisher's note}

Springer Nature remains neutral with regard to jurisdictional claims in published maps and institutional affiliations.

\section{RELATED LINKS}

European Creutzfeldt-Jakob Disease Surveillance Network

(EuroCJD): https://www.eurocjd.ed.ac.uk

(c) Springer Nature Limited 2021 